\title{
PERSPECTIVAS DEL ESTADO EN EL EJERCICIO DE NUEVAS POLÍTICAS PÚBLICAS EN EL PERÚ: Una revisión panorámica de las políticas promotoras del crecimiento económico*
}

\author{
Miguel Pisfil Capuñay \\ UNIVERSIDAD NACIONAL MAYOR DE SAN MARCOS \\ mpisfil@terra.com.pe
}

\begin{abstract}
Resumen
En este ensayo se pretende hallar elementos fácticos y sistematizar lineamientos teóricos que aporten a la comprensión de la relación consustancial entre el Estado -con sus instituciones- y la sociedad civil, así como proporcionar algunas luces sobre el divorcio total que existe entre estos dos estamentos en las dimensiones social y política. En particular, se busca sistematizar las principales políticas públicas que guardan estrecha relación con el crecimiento económico, identificar cuáles se ejercitan con ineficiencia y cuáles con eficiencia en la asignación de los recursos públicos, reseñar algunas experiencias latinoamericanas de implantación exitosa de políticas públicas y delinear para nuestro país políticas nuevas que tengan por meta promover un esfuerzo social articulado en pos de la estructuración de una estrategia nacional de desarrollo productivo. Dado su alto impacto en lo social y en lo económico, estas nuevas políticas se convertirían en pivotes de las tradicionales (sectoriales y sociales).
\end{abstract}

Palabras clave: Estado, políticas públicas, eficiencia, innovación, desarrollo tecnológico, empresarialidad, afianzamiento institucional.

\begin{abstract}
The purpose of this study is finding factual elements and systematizing theoretical guidelines which contribute to the understanding of the circumstantial relationship between the State -with its institutions-and civil society, as well as shedding light on the total separation existing between these two groups in social and political contexts. Particularly, we have tried to systematize the principal public policies which have a close relationship with economic growth, identify which work efficiently or not in allocating public resources, report on some Latin-American experiences on the successful implementation of public policies and outline new policies for our country which aim at promoting an articulated social approach for the structuring of a national strategy for productive development. Given its high impact in both social and economic fronts, these new policies shall become pivots for the traditional policies (sectorial and social).
\end{abstract}

Key words: State, public policies, efficiency, innovation, technological development, entrepreneurship, institutional strengthening.

* Basado en la tesina del mismo título presentada por el autor en octubre del 2005 para obtener el grado de máster en Gerencia Pública para Directivos Iberoamericanos, posgrado organizado para el Perú por la Fundación Internacional para Iberoamérica de Administración y Políticas Públicas (FIIAPP), de España, en convenio con la Presidencia del Consejo de Ministros del Perú y la Universidad ESAN, con apoyo económico de la Agencia Española de Cooperación Internacional. 


\section{Teoría: políticas públicas y crecimiento económico}

\subsection{El modelo weberiano de administración pública y el paradigma posburocrático}

El concepto de organización burocrática («racional-legal») desarrollado por Max Weber, el padre de la sociología moderna, es uno de los primeros y más influyentes aportes del pensamiento europeo al management. En 1918, en su obra Economía y sociedad, Weber formuló el concepto de organización burocrática, cuyas principales características estructurales se pueden resumir en:

a) Una jerarquía de autoridad establecida con exactitud.

b) Un sólido sistema de líneas verticales de comunicación que han de ser observadas.

c) Una división reglamentada del trabajo y basada en la especialización.

d) Un sistema de reglas y principios que establece los derechos y deberes de todos los miembros de la organización.

e) Un sistema de formas de procedimiento exactamente definidas para la realización de las tareas.

De acuerdo con el modelo weberiano de organización burocrática, la administración pública se concibe como un organismo con elevada capacidad de adecuación, rapidez de acción, precisión, fidelidad a las normas y efectividad en la acción administrativa. La burocracia basada en estos principios y con los criterios de rendimiento y antigüedad goza de una adecuación funcional óptima; se dice que posee las características estructurales propias de una maquinaria pública jerárquica y de perfecta sincronización interna, dotada de una muy competente plantilla de servidores, cuya selección se basa en su cualificación y méritos.

Sin embargo, algunos autores sostienen que la combinación entre la sujeción estricta a las normas, la total dependencia jerárquica y las competencias estrictamente establecidas que caracterizan al «paradigma burocrático» origina una disminución de la capacidad de adaptación y de innovación de la organización burocrática. Se reconoce que para contextos de grandes cambios sociopolíticos este tipo de organización resulta rígida, lenta y hasta ineficaz.

Por esta razón, muchos países buscan resolver estas limitaciones mediante ajustes administrativos; esto es, diseñando estructuras más planas, sin tantos niveles orgánicos de decisión (no más de dos), o apelando a la delegación de competencias.

Conforme a la tradición estatal del capitalismo de Occidente, las acciones del Estado de Bienestar se orientan a la regulación del ciclo económico y se sustentan en una organización y gestión de corte esencialmente weberiano. En largos periodos de la historia, el sector público peruano funcionó con los principios señalados por Weber, los que se resumen en el cuadro 1 .

En general, los procesos de crítica al viejo paradigma burocrático y de reforma institucional se han basado en tres tipos de consideraciones: ideológicas (el Estado inhibe toda iniciativa individual), de carácter político (la producción de bienes públicos está dictada por los productores y no por los intereses de los ciudadanos, que son los consumidores) y de cuestionamiento a las grandes estructuras jerárquicas para adaptarse con eficiencia a los 


\section{Cuadro 1. Tipos de administraciones públicas}

\section{El paradigma burocrático}

1. Interés público.

2. Eficiencia.

3. Administración.

4. Control.

5. Funciones, autoridad y especialización estructural.

6. Justificación de costos.

7. Responsabilidad impuesta.

8. Reglas y procedimientos.

9. Sistemas administrativos.

\section{El paradigma posburocrático}

1. Valorar los resultados para los ciudadanos.

2. Calidad y valor.

3. Producción.

4. Adhesión a las normas.

5. Identificar misiones, servicios y resultados.

6. Valor de la prestación.

7. Construir responsabilidad y prestar atención a los recursos humanos.

8. Comprometerse con los problemas e innovar.

9. Introducir el mercado, la elección, los incentivos y la evaluación.

Fuente: Brugue. Gestión pública y democracia. Citado por Manuel Pinto en su material de clase: La modernización de las administraciones públicas; por un nuevo modelo de administración pública. ESAN, diciembre del 2004.

procesos de transformación tecnológica y económica de las últimas décadas.

En nuestro país, durante la década del noventa, la conjunción de estos elementos de presión (con fuerte acento ideológico) más la exagerada discrecionalidad política (del Ejecutivo, de los legisladores y hasta de los altos niveles de la burocracia estatal) terminaron por desvirtuar la naturaleza de la organización pública, y muchos componentes centrales de este modelo fueron arrasados por la ola antiestatal de la época.

Debe destacarse que desde los años noventa se ha dado impulso al ejercicio del rol regulador del Estado conforme al principio de reglas, es decir, orientado por un nuevo enfoque que pone énfasis en el ejercicio de la función reguladora de las prácticas de los agentes económicos utilizando mecanismos de mercado. Ello como consecuencia de la masiva privatización de los activos públicos, del fomen- to de la libertad de empresa y de la necesidad de aplicar técnicas universales de regulación a los monopolios naturales originados por las olas privatizadoras. Este rol regulador, sin embargo, no ha resultado más que un esfuerzo renovado por hacer lo mismo. Si bien se ejercen las políticas reguladoras con nueva óptica, esto es, buscando impactos sobre la eficiencia, con más transparencia y con un sistema institucional impecable por la profesionalidad de su burocracia, esta función no deja de tener relación con un conjunto de políticas orientadas siempre a enfrentar los problemas económicos, sociales y políticos de corto plazo.

Como veremos enseguida, en el Perú persiste una situación de crisis política y de frágil institucionalidad que rodea las políticas públicas y obligará al Estado a hacer un giro sustancial en su funcionalidad, mediante el ejercicio de nuevas políticas públicas cuya trascendencia apunte más allá del corto plazo. Ello exigirá una 
transformación de los roles del Estado o al menos un nuevo énfasis en la práctica de aquellos que ejerce con deficiencia y, consecuentemente, demandan una transformación de su sistema de administración pública; en general, de todo el macroproceso de hacer la cosa pública.

\subsection{Las políticas públicas}

Se dice que las políticas públicas constituyen:

... el vector que sintetiza el conjunto de proposiciones, decisiones y operaciones dinámicas e interdependientes entre actores políticos, sociales e institucionales, a través de las cuales se busca desde el gobierno imprimir un determinado rumbo a la sociedad y el Estado que se gobiernan (Medellín Torres, 1997).

Oszlak y O’Donnell (1976), de otro lado, definen las políticas públicas como:

... un conjunto de reacciones y omisiones que manifiestan una determinada modalidad de intervención del Estado en relación con una cuestión que concita la atención, interés o movilización de otros sectores de la sociedad civil.

Sin embargo, según el enfoque del régimen político, las políticas públicas adquieren una doble connotación. Por una parte, desde una perspectiva macro las políticas públicas se definen como el rasgo gubernativo de todo régimen político, es decir, se conciben como el recurso a través del cual la función gubernativa hace que la interacción orgánica entre el Estado, el régimen político y el aparato estatal se exprese y cumpla dentro de un orden establecido. Por otra parte, desde una perspectiva micro las políticas públicas se definen como un curso de acción gubernativa a través del cual los gobiernos hacen que la interacción orgánica entre el Estado y la sociedad se exprese y cumpla con un propósito definido.

\subsubsection{Las políticas públicas y la estructuración de políticas públicas}

Las preocupaciones por las políticas públicas se han enmarcado en dos grandes vertientes interpretativas: en la acción y en la racionalidad. En el primer caso, los estudios, análisis y diseños orientados a la acción suponen que existe una plausible correlación entre el conocimiento de la acción y la mejora de las actuaciones gubernamentales. De modo que se difunde la creencia de que los expertos tienen la tarea de contribuir al funcionamiento del sistema, no a su cuestionamiento ni a un conocimiento que no sea práctico a corto plazo. El segundo enfoque privilegia los problemas que surgen en torno al mayor o menor grado de racionalidad que existe en la formación y trazado de las políticas públicas. Se desprende que estas políticas están regidas por una construcción secuencial directa del tipo finesmedios-producto-impactos o bien que los trazados de políticas se rigen por una actitud más incrementalista, basada en una relación ensayo-error.

Conforme a Medellín Torres (1997:12), debemos apuntar que las experiencias de reformas estructurales y de redimensionamiento del Estado en América Latina:

... han sido escenario para la incorporación de nuevos contenidos en las políticas públicas: en su función estratégica, las políticas públicas definen los parámetros y las modalidades de interacción entre lo público y lo privado; concretan las condi- 
ciones para traducir los principios de flexibilidad y autonomía en ejes de una acción pública selectiva, eficaz y eficiente; definen cuáles son los asuntos que alcanzan el rango de interés público, para ser incluidos en la agenda de gobierno; y describen los niveles de homogeneidad y armonía que rigen la gestión integradora de los mercados y las economías nacionales. En su condición institucional, las políticas públicas no solo expresan la particular configuración de las estructuras, funciones y procedimientos que rigen al Estado y a las organizaciones públicas, sino que también revelan la particular dinámica conflictiva en que se desenvuelve la acción pública. En su relación con las estructuras políticas, las políticas públicas expresan tanto una particular movilidad de las fuerzas políticas, con una dinámica específica de incorporación o exclusión (política, económica y social) de los ciudadanos con respecto a los asuntos del Estado. $\mathrm{Y}$ en su relación con la sociedad civil, las políticas públicas se constituyen en un poderoso instrumento de comunicación.

Asimismo, los especialistas sostienen que la estructuración de las políticas públicas depende, entre otros factores, de la centralidad del régimen político y de la función gubernamental. El primer factor permite una aproximación más precisa a los problemas de consistencia y persistencia de la democracia, mientras el segundo permite dimensionar la capacidad estructural del Estado para producir los resultados que la sociedad le reclama.

Cuatro grandes razones justifican la centralidad del régimen político en el conjunto de relaciones Estado-aparato estatal-sociedad. En primer lugar, el régimen político es la instancia que le confiere corporeidad e identidad a la idea abstracta de
Estado, bajo la forma de aparato estatal. En segundo lugar, el régimen político le confiere organicidad y orden al conjunto de relaciones que se entretejen en torno al Estado y la sociedad. Define e imprime un determinado sentido normativo y contenido valorativo a las relaciones sociales. En tercer lugar, el régimen político permite que el Estado se proyecte como un generador de orden interno y externo, es decir, de consistencia y unicidad de las instituciones y de la sociedad, respectivamente. En cuarto lugar, el régimen político constituye la instancia a través de la cual el Estado confiere poder y autoridad formal a los gobernantes para tomar las decisiones; define competencias para comprometer, asignar y aplicar los recursos públicos; finalmente, establece los controles y fija las modalidades y los márgenes de participación de los actores ciudadanos y comunidades en las decisiones y en la fiscalización de la acción pública.

En el caso del Perú, las políticas públicas deben ser analizadas en el contexto de una precariedad política evidente y una informalidad institucional generalizada, que tipifica una forma particular de estructurar políticas públicas en países de frágil institucionalidad.

Medellín Torres (2004) sostiene que la política pública en países con problemas de poca autonomía gubernativa, como el Perú, se caracteriza por: a) una resistencia institucional a la planeación y la evaluación de las políticas públicas, b) la desconexión entre los procesos de planeación y los de presupuestación, c) la prevalencia de rígidos sistemas de control que obstaculizan la acción gubernamental, d) una excesiva concentración del poder y la usurpación de funciones en favor de unas determinadas entidades y organismos 
públicos, e) inestabilidad en los altos cargos ministeriales, que se expresa en alta inestabilidad de las políticas públicas, y f) una tendencia a elaborar las agendas públicas en función de los deseos de quien gobierna.

Aquí, el Estado y el gobierno no son capaces de mantener la unidad del poder político institucionalizado ni la unidad de acción de sus instituciones. Están muy lejos de aplicar modelos del tipo Escuela de Diseño o similares ${ }^{1}$.

La estructuración de las políticas públicas se define como el proceso mediante el cual un gobernante busca que las intenciones del gobierno adquieran y proyecten las formas, relaciones y significados gubernativos sobre las instituciones y la sociedad que gobierna. La estructuración de las políticas comprende dos grandes momentos: la formación de las políticas y el trazado de las políticas.
La formación de las políticas da cuenta de los distintos elementos y factores que intervienen para que una decisión política se produzca y tenga una dirección bien determinada. El trazado de las políticas comprende el trayecto que va desde la formalización de la decisión política y su traducción en un enunciado de política pública hasta su despliegue espacial (ver Medellín Torres 2004: 34).

\subsubsection{La evaluación de políticas públicas}

La evaluación es la valoración sistemática de la operación y los resultados de un programa o política por medio de su comparación con un conjunto de estándares explícitos o implícitos que contribuyen a su mejora. Además, es interactiva con todos los procesos y momentos del ciclo de las políticas, como lo muestra la $f i$ gura 1.

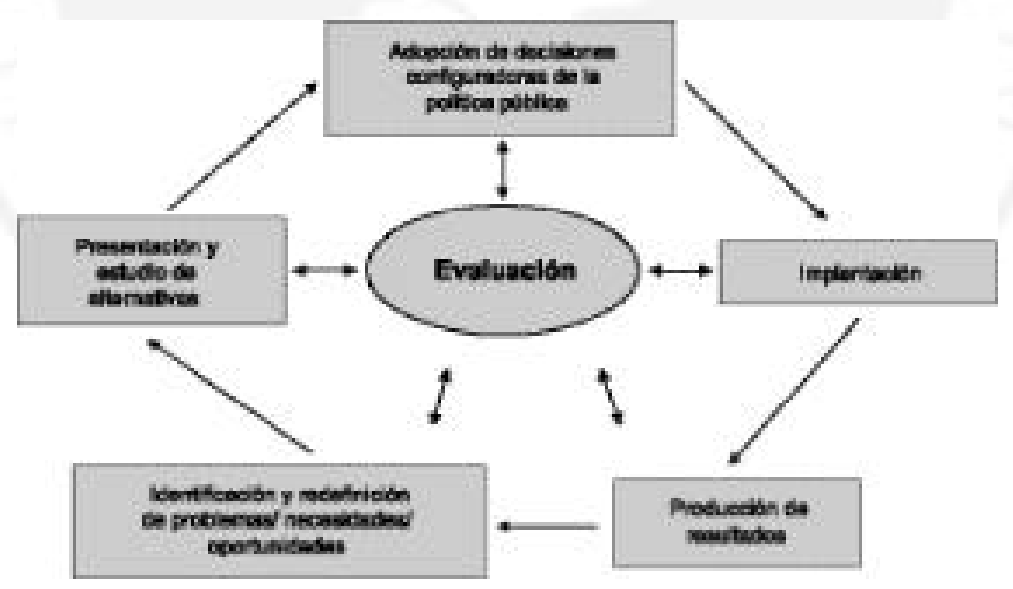

Figura 1

El ciclo de la política pública

1. Sin embargo, tampoco se sostiene la tesis que exagera la desarticulación de las facetas del proceso de políticas públicas, como ocurre en el llamado modelo «cesto de la basura» de Michael Cohen, James March y Johan Olsen (1972), citados por Eugenio Lahera (2004). 
En ese sentido, puede hacerse:

a) Evaluación de la conceptualización y del diseño de los programas.

b) Evaluación de la implementación de los programas.

c) Evaluación de la eficacia o impacto de los programas.

d) Evaluación de la eficiencia de los programas.

La medición de los impactos de las políticas públicas no resulta conceptualmente fácil, como la comprensión de los cambios que ejerce una variable independiente (en este caso la política estatal) en su relación con un conjunto de variables independientes.

Si las políticas estatales son parte de un proceso social tejido alrededor de cuestiones, y si a él concurren políticas de actores privados que pueden tener gran peso sobre el curso de acción seguido por los eventos estudiados, el tema de los impactos se complica enormemente. Dado X cambio en cierta característica $\mathrm{Z}$, ¿qué proporción de ese cambio podemos atribuirlo causalmente a políticas estatales, a políticas privadas y a otros factores ajenos a unas y a otras? Oszlak (1981).

Es el caso de la política comercial de los últimos años, cuyo éxito descansa fundamentalmente en las favorables condiciones del mercado internacional y en la exitosa incursión de los productores privados corporativos y emprendedores antes que en el diseño y la implementación de una política comercial activa e integradora (que incluya políticas específicas de promoción de las exportaciones: cambiarias, crediticias y/o arancelarias) desde el sector público, como veremos en la sección 3 .
En nuestro país, puede simplemente no haber evaluación de políticas públicas en la mayor parte de la actividad pública, con lo que la pérdida de eficiencia y efectividad potencial es enorme. De hecho hay un nivel de evaluación parcial ad hoc para resultar coincidente con una opción elegida de antemano, pero no como un proceso de evaluación interactiva ${ }^{2}$. Más aun, se evalúan políticas de menor trascendencia en vez de las más importantes y complejas; o la evaluación que se hace no se conecta con el ciclo, para retroalimentar la política pública, ni tampoco se articula con las políticas sectoriales vinculantes.

\subsection{Las políticas públicas y el crecimiento económico}

Conforme a los procesos histórico-sociales, se dice que las políticas públicas ejercen un rol de primer orden en el crecimiento económico de las naciones. En particular, para este estudio interesa evaluar dos variables determinantes de la senda del crecimiento: el fomento y la protección de las innovaciones, y la promoción e implantación de una red de infraestructura productiva. Por un lado, el rol tutelar de los derechos de propiedad y de un sistema de patentes y, por otro lado, la vigencia de un sistema de infraestructura cuya capacidad se adapte adecuadamente al impulso del proceso inversor privado (corporativo y emprendedor) destacan

2. Entendemos por evaluación interactiva el «proceso de investigación participativa que analiza la organización, el funcionamiento y desarrollo de un programa en relación con sus objetivos, las expectativas de los participantes y los resultados obtenidos. Ella está basada en la interacción directa o indirecta de los usuarios de los programas, de estos con los técnicos y de los técnicos con los directivos» (Lahera, 2004: 23). 
entre las políticas activas que ejercen las instituciones del Estado con miras al desarrollo económico.

\subsubsection{La innovación, patentes y rol tutelar del Estado}

Tanto las innovaciones como los derechos de propiedad intelectual poseen una relación unidireccional, en el sentido en que no pueden existir innovaciones sin derechos de propiedad definidos por el Estado. Es decir, el proceso innovador de una colectividad, entendido como un proceso ininterrumpido de conocimientos, imaginación, innovación, propiedad intelectual y solución en forma de productos mejorados y nuevas tecnologías, es un poderoso impulsor del desarrollo.

Como bien precisa Benavides (1998), la innovación es un proceso cuyo fin último es obtener nuevos productos y/o procesos productivos -en ocasiones también nuevas tecnologías-. Por su parte, la tecnología refleja un conjunto de técnicas industriales susceptibles de ser aplicadas a un proceso productivo. Más allá de las técnicas industriales, la innovación puede consistir en la creación de algo más liviano -como añadir una nueva función a un producto con la tecnología existente, por ejemplo- o, por el contrario, puede implicar cambios más profundos basados en avances científicos y tecnológicos. En este último caso se habla de innovación tecnológica.

Como sabemos, el enfoque schumpeteriano de la innovación distingue dos modelos: el primero, conocido como Schumpeter Mark I (1911) o de destrucción creativa, introduce la noción del empresario innovador, creador de su propia empresa, que utiliza el conjunto de cono- cimientos ya existentes para introducir una innovación en el mercado. El innovador precipita la obsolescencia y declive de las empresas existentes y goza de un periodo de monopolio (de ganancias supranormales) que termina con la entrada de imitadores. El segundo modelo, Schumpeter Mark II (1939) o de acumulación creadora es el caso de un régimen tecnológico en donde la innovación pasa a convertirse en una actividad sistemática de las empresas grandes, con capacidad de destinar recursos a la investigación y desarrollo (I \& D), y el mercado tiende a presentar un índice de concentración elevado. En ambos casos, el proceso innovador se convierte en una fuerza endógena sui géneris.

Con relación al ciclo tecnológico (ver figura 2), Carlota Pérez (2003) sostiene:

Después de que una innovación radical da lugar a la aparición de un nuevo producto capaz de crear una nueva industria, hay un período inicial en que se registran más innovaciones y una optimización, que trae consigo la aceptación del producto en el segmento correspondiente del mercado. La interacción con el mercado pronto determina la dirección de las mejoras, definiendo a menudo un diseño dominante; a partir de aquí, y a medida que crecen los mercados, se registran innovaciones incrementales sucesivas para mejorar la calidad del producto, la productividad del proceso y la situación de los productores en el mercado. Al final se llega al pleno desarrollo o madurez, cuando una inversión adicional en innovaciones produce rendimientos decrecientes. Según la importancia que tenga el producto, todo el proceso puede durar unos pocos años o varios decenios. En este último caso, las «mejoras» suelen comportar una sucesión de modelos. 


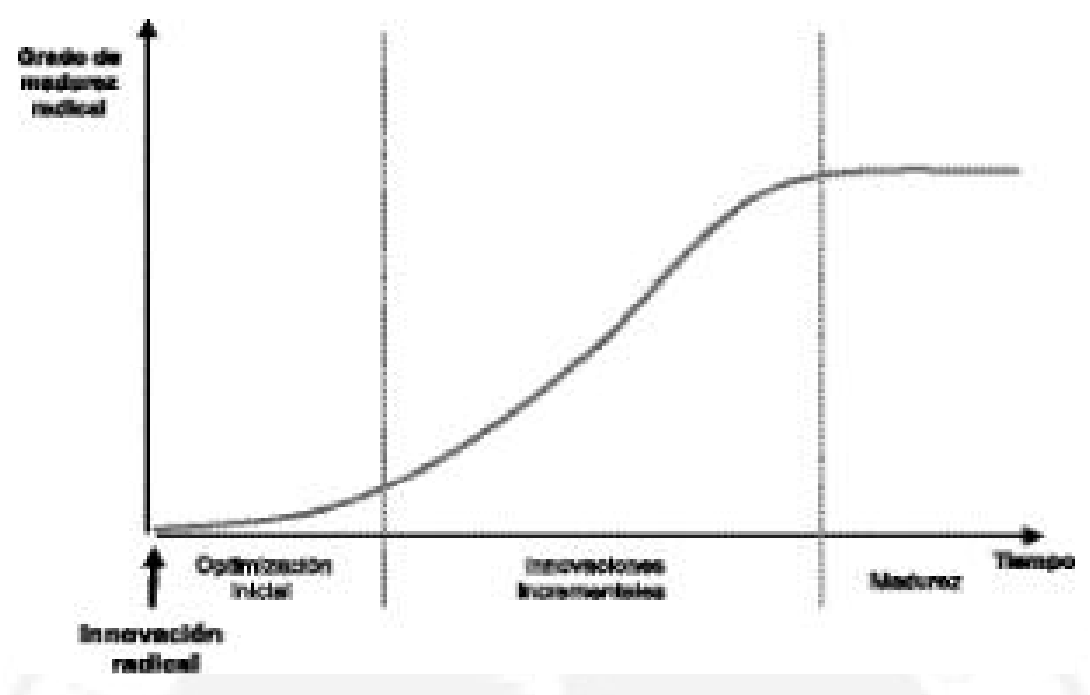

Figura 2. Evolución de una tecnología (trayectoria tecnológica)

De otro lado, interesa destacar la innovación como un proceso de aprendizaje dinámico que a partir de un nivel de conocimiento inicial crea nuevo conocimiento y lo irradia a los productos y procesos productivos de la empresa; por lo general, sobre la base del proceso learning by doing, sugerido por Arrow (1962), o learning by using, de Rosenberg (1979), o learning by failing, desarrollado por Maidique y Hayes (1984).

En general y de modo abreviado, podemos señalar que el proceso de innovación tecnológica tiene las siguientes características:

a) Es de naturaleza continua.

b) Está sujeto a condiciones históricas, es decir, su evolución depende de su trayectoria pasada (path dependency).

c) Es irreversible, en la medida en que los mecanismos de retroalimentación fortalecen su vigencia en detrimento de otras opciones tecnológicas sucedáneas.

d) Está asociado a la incertidumbre de tres tipos: la técnica, la del mercado y la del futuro.

\subsubsection{Inversión en infraestructura y crecimiento}

Las redes de infraestructura constituyen un elemento vertebrador de la estructura económica de los países y de los mercados, así como de los mecanismos de articulación con la economía mundial, al hacer posible la materialización de los flujos de comercio. Destacan las infraestructuras de transporte, de energía y de comunicaciones y las redes de agua potable y de saneamiento.

Las inversiones en infraestructura contribuyen al crecimiento del producto e impactan sobre cuatro aspectos del desarrollo económico en los espacios territo- 
riales donde se realizan: la estructura de costos de las empresas, la productividad de los factores, la conectividad y accesibilidad territorial, y el bienestar general de la población.

En armonía con las implicancias de las teorías del crecimiento económico, sostenemos como Rozas y Sánchez (2004: 62) que:

... la provisión de infraestructura básica es un factor diferencial clave en la explicación de las brechas de crecimiento: la reducción en los costos de transporte, energía, telecomunicaciones y otros, y la mejora en las características de operación en cada actividad permiten a los agentes económicos un acceso más eficiente a los mercados de insumos y productos, y reducen en consecuencia los costos de transacción. Esto hace posible reorganizar la estructura industrial, aumentar la productividad de los factores e incrementar la producción. A la vez estas diferencias producidas en la forma que un aumento de la infraestructura se traduce en mejoras de la productividad se explican por las diferencias existentes en la calidad de las prestaciones y su entorno institucional.

Sin embargo, la relación estimada entre infraestructura y crecimiento no es lineal: el efecto positivo de las inversiones en infraestructura sobre el crecimiento es decreciente. Ello sugiere que las inversiones en ampliación de redes de infraestructura deben acompañarse de otras medidas, por lo que se desprende que existen condiciones necesarias distintas de las condiciones suficientes para que una mejora en la infraestructura física apoye eficazmente el crecimiento económico. Esta característica es de singular importancia para el diseño e implementación de políticas de Estado. En efecto, el impacto de las inversiones en infraestructura sobre el crecimiento dependerá de su articulación con otros factores, tales como el grado de desarrollo del capital humano, la dotación de recursos humanos y el acceso al financiamiento y a la tecnología, entre otros. La cantidad, calidad y eficiencia de los servicios de infraestructura estarán determinadas por la interacción de los componentes esenciales de los mercados del sector: infraestructura física, condiciones creadas por las políticas sectoriales, regulación de la actividad y características de los mercados. Este enfoque será de mucha utilidad para el estudio de los impactos de las políticas sectoriales pesquera, agroindustrial y de concesiones forestales que se verán en la siguiente sección.

\section{El estado actual de las políticas públicas en el Perú}

\subsection{Algunos supuestos de análisis}

En general, las siguientes premisas delimitan una política pública:

a) Una política pública es siempre un proceso de acción y se configura como un proceso de procesos.

b) Es una construcción analítica y se estructura a través de la conexión de un ámbito de problemas, de necesidades y/o de oportunidades, de un lado, y la acción (real o potencial) de una o varias instancias de gobierno, por otro lado.

c) Las políticas son públicas (no privadas), pueden serlo por inacción de algunos gestores, y también incluyen a sus contrarias, a las antipolíticas, las políticas cuyos resultados o impacto real son opuestos al resultado o impacto deseado. 
d) Nunca parte de cero -es herencia de la acción o inacción del pasado- ni puede considerarse ajena a la influencia de otras políticas.

De otro lado, siguiendo a Lahera (2004), debemos apuntar que las políticas públicas de excelencia tienen las siguientes características:

a) Fundamentación amplia y no solo específica (la idea central y la ruta).

b) Estimación de costos y de alternativas de financiamiento.

c) Factores para una evaluación de costo-beneficio social.

d) Beneficio social marginal comparado con el de otras políticas (las prioridades).

e) Consistencia interna y agregada (vinculación con otras políticas).

f) De apoyos y críticas probables (políticas, corporativas, académicas).

g) Oportunidad política.

h) Lugar en la secuencia de medidas pertinentes (¿qué es primero?, ¿qué condiciona qué?).

i) Claridad de objetivos y funcionalidad de los instrumentos.

j) Indicadores (costo unitario, economía, eficacia, eficiencia).

Las políticas públicas de excelencia incluyen tanto el aspecto político como su origen, objetivo, justificación o explicación pública, y deben estar enmarcadas en un amplio proceso de participación, evitando el sesgo de los actores públicos hacia la tecnocracia o el populismo.

Aún la excelencia formal de las políticas públicas no es una garantía respecto de la corrección de sus contenidos sustan- tivos, los que pueden terminar siendo perfectamente equivocados o inconsistentes con los mecanismos propuestos o las soluciones definidas por las mismas políticas. De hecho, las políticas públicas habitualmente son un second best respecto de una política óptima en lo sustantivo, la que puede no existir.

Estos elementos conceptuales son de importancia en la revisión de los principales avances en materia de políticas públicas en nuestro país, donde, como hemos sostenido antes, persisten serios problemas de inconsistencia, insuficiencia de recursos públicos comprometidos y bajo impacto social, en especial en educación y salud.

\subsection{Las políticas públicas sectoriales más relevantes}

Compartimos la idea de Lahera (2004) cuando sostiene que:

... una política pública de excelencia corresponde a aquellos cursos de acción y flujos de información relacionados con un objetivo político definido en forma democrática; los que son desarrollados por el sector público y, frecuentemente, con la participación de la comunidad y el sector privado. Una política pública de calidad incluirá orientaciones o contenidos, instrumentos o mecanismos, definiciones o modificaciones institucionales, y la previsión de sus resultados...

En esta línea de análisis, podemos sostener que las políticas públicas de este tipo en el Perú son escasas y la mayor parte se concentran en las políticas económicas (fiscal, monetaria, cambiaria y crediticia), que son las que mejor funcionan actualmente por la complejidad técnica de estos 
ámbitos de la acción pública, la elevada especialización de su burocracia y por mantener la mayor independencia respecto de la discrecionalidad política (distantes de los afanes de política del Ejecutivo y del Legislativo); asimismo, por las externalidades positivas que el buen rumbo macroeconómico de los últimos años ha causado en la administración tributaria (Sunat). Excepcionalmente, se encuentran algunos ejemplos de excelencia en sectores con cierto expertise en proyectos macroeconómicos y sociales de amplio alcance y que cuentan con asistencia financiera y técnica de organismos internacionales, como los programas de salud materno-infantiles, los programas de reforma judicial (a pesar de su escaso impacto social), los programas de reforma educativa (aunque de baja eficacia, escasa difusión de sus logros y magros resultados en el ámbito continental). También deben destacarse los proyectos participativos del Programa de Caminos Rurales del Ministerio de Transportes y Comunicaciones con más de 600 microempresas de mantenimiento vial (con reconocimiento del Banco Mundial por su excelencia en la gestión del proyecto) y algunos programas de alcance social dirigidos por organismos internacionales y el Ministerio de la $\mathrm{Mu}$ jer (ver cuadro 2).

Los resultados de las políticas de educación y de salud en el ámbito de la gestión pública entre países de América del Sur se muestran en la figura 2, con base en el informe: Estado de la población mundial 2005, del Fondo de Población de las Naciones Unidas. Nuestro país ocupa el penúltimo lugar en materia de salud, alfabetismo y educación primaria, pese a la mejora en la gestión sectorial alcanzada en los últimos tres años.
Mientras Colombia asigna el 6,7 por ciento del PBI al gasto en salud pública, nuestro país destina solamente el 2,2 por ciento del $\mathrm{PBI}^{3}$. La esperanza de vida al nacer sigue siendo baja (73\%) y la tasa de mortalidad infantil (31 por cada $10 \mathrm{mil}$ ) ha bajado con relación a la década del noventa; empero, es la más alta después de Paraguay y Bolivia.

Persisten los problemas sistémicos en educación y las desigualdades de género y de índole espacial (rural-urbano), expresadas por las diferencias notables en las tasas de analfabetismo -más altas en mujeres y en la población rural-, así como en la insuficiencia de recursos públicos (apenas el 2,8\% del PBI). El Perú es la segunda de las naciones latinoamericanas que menos invierte en el fomento de la calidad del capital humano vía el conocimiento y el aprendizaje.

Estos casos de políticas públicas -en salud y educación- muestran con elocuencia la falta de visión y estrategia del Estado, la existencia de una agenda pública sin ordenamiento de jerarquías vitales para la acción, y la insuficiencia de la logística y

3. En su estudio «La carga económica de la enfermedad diarreica aguda en niños menores de 3 años en localidades de la sierra y selva del Perú», José Arca Vera estimó -con base en un trabajo de campo aplicado en tres localidades de pobreza extrema representativas de estas regiones- que el 64\% de la carga económica para el tratamiento de la enfermedad diarreica aguda es cubierta por la población, mientras el restante $36 \%$ corresponde a los centros hospitalarios públicos, lo cual revela no sólo problemas de equidad y eficiencia, sino también de solidaridad y universalidad en la gestión de los recursos públicos destinados a la salud. (Tesis de magíster en Economía de la Salud, UNMSM, 2004). 


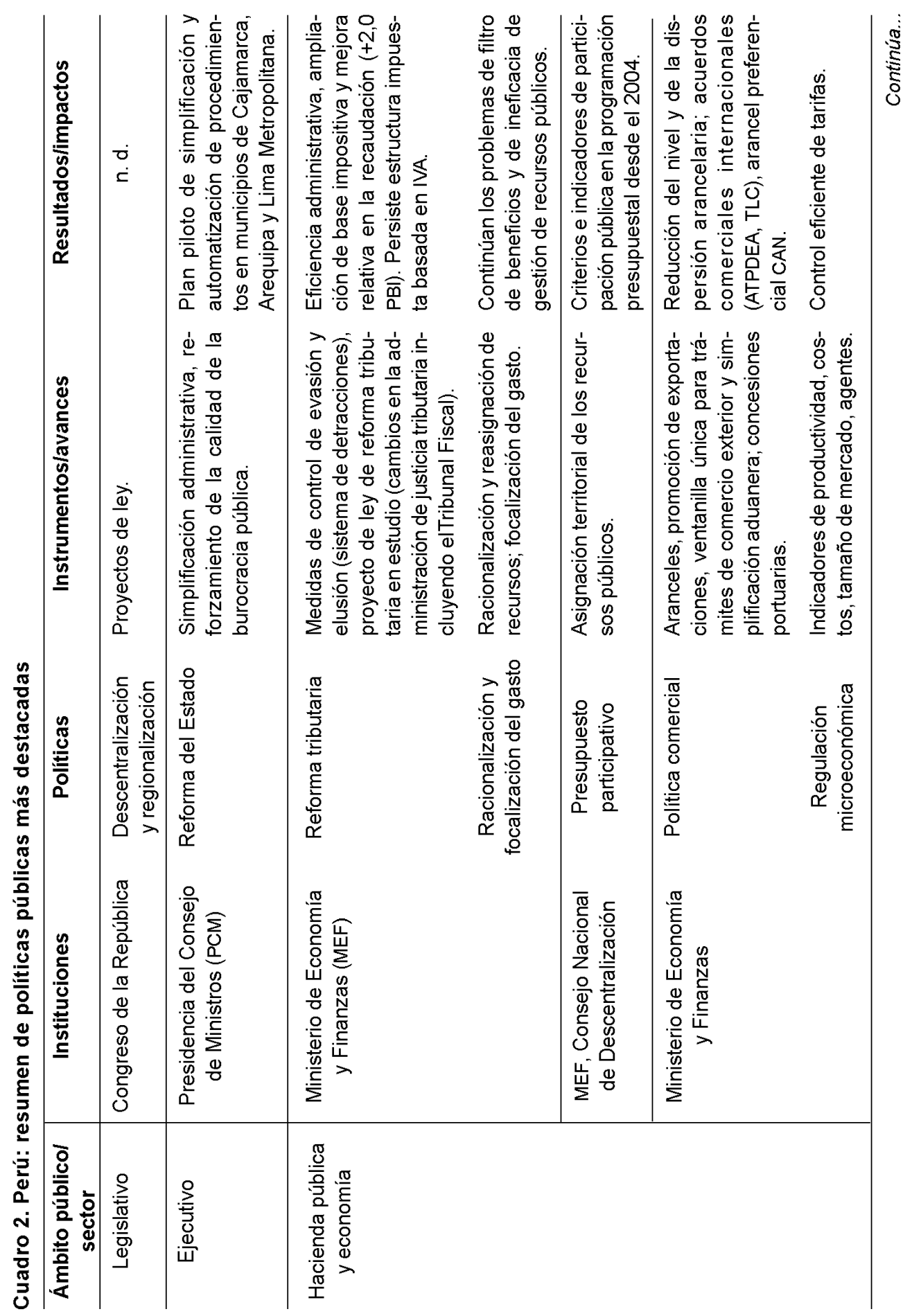




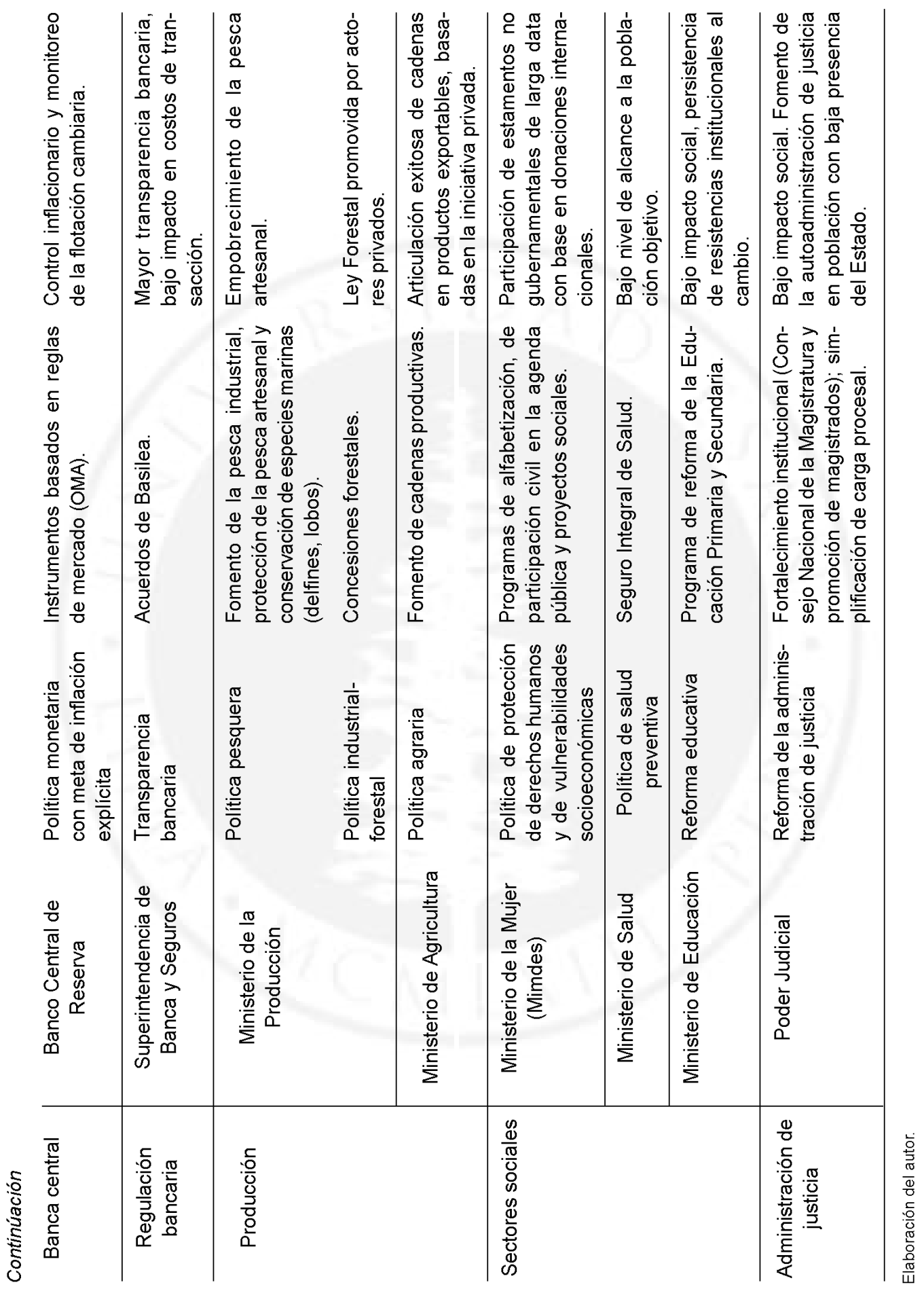



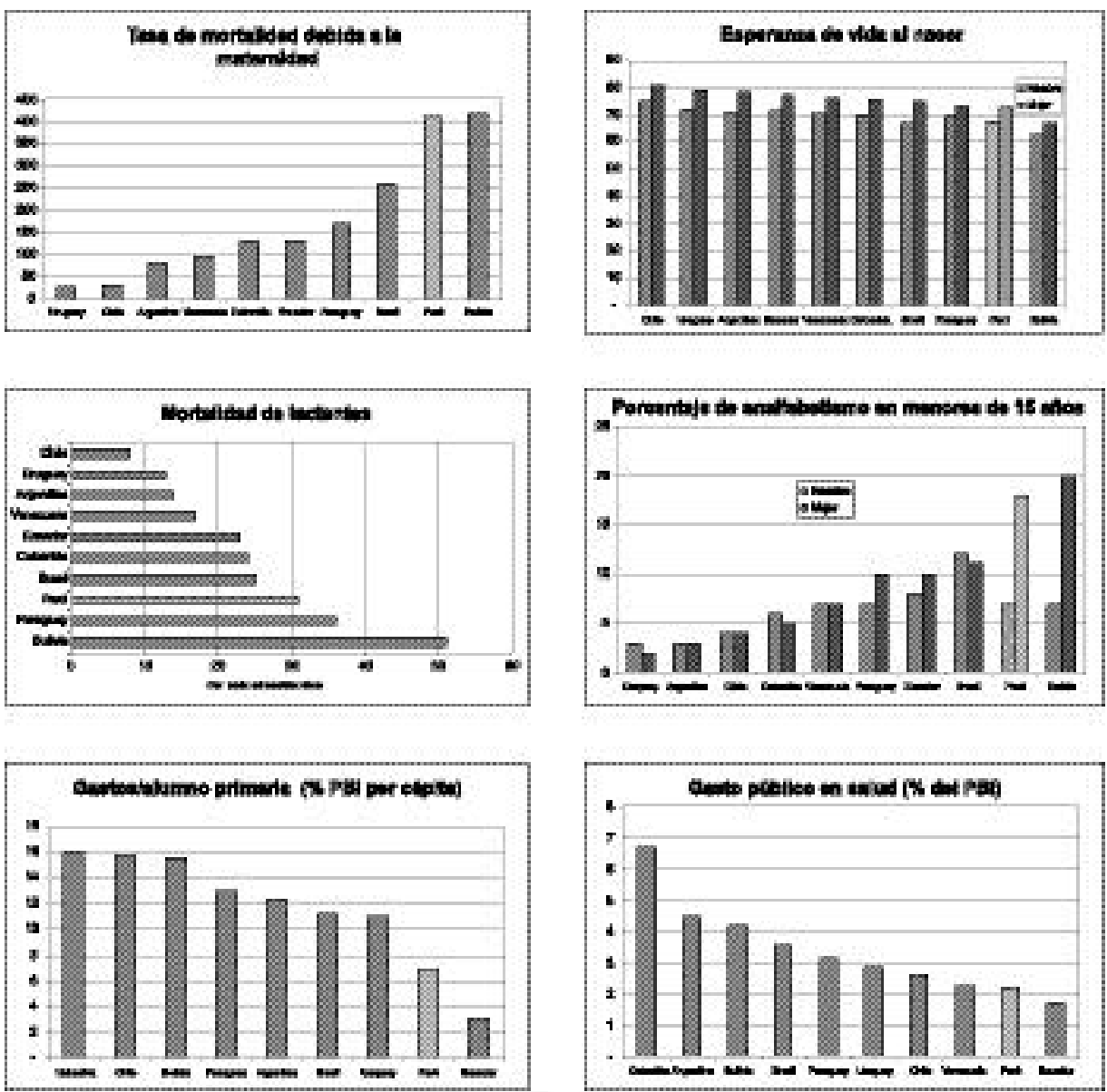

Fuente: Fondo de Población de las Naciones Unidas, 2005.

Figura 3

Perú: Indicadores de salud y educación en relación con otras naciones de América Latina 
los recursos burocráticos gestores de la salud y la educación ${ }^{4}$. Sin embargo, debemos destacar que, según observaciones de Patricia Arregui, experta de Grade, las brechas se están acortando desde 1998, pues se ha registrado una mayor permanencia de los estudiantes en primaria al eliminarse la repetición del primer año, que era el factor que determinaba la estadía (o explicaba la deserción) de muchos niños en las escuelas públicas.

En otros ámbitos de las políticas públicas prima la agenda institucional o política sobre la agenda sistémica, por la urgencia de atender problemas a punto de causar un estallido social o por la presión de grupos sociales de interés, lo que configura un proceso de decisión política de baja autonomía gubernativa, dada la alta diseminación del poder y la existencia de micropoderes ${ }^{5}$.

4. Con un enfoque más integral, empero, compartimos la evaluación de la gestión de la salud pública del doctor Uriel García (prestigioso ex ministro de Salud) cuando sostiene:

El ejemplo paradigmático de la patología de la pobreza en el Perú es la tuberculosis. Nuestro país, según la Organización Mundial de la Salud, tiene un excelente programa de lucha antituberculosis. Consiste en captar, con un simple y baratísimo análisis, a los enfermos, para luego tratarlos con medicamentos en forma gratuita. Pero, como la tuberculosis es producto del hacinamiento en miserables viviendas, falta de un salario adecuado, alimentación, educación, en los diez años de ejecutado este plan le han hecho una magra mella. El Perú hoy día tiene altos índices de incidencia y de mortalidad. La tuberculosis como el cáncer del cuello uterino, las enfermedades por contagio fecal-oral, la neumonía del recién nacido y otros males no se curan con medicamentos sino con justicia social. (Medicina y pobreza. El Comercio. Lima, 12 de oct. del 2005, pág. A5).

5. Veamos un caso. En un trabajo sobre gestión de los recursos regionales y gasto social, publicado por la Universidad del Pacífico, Enrique Vásquez señala que el 50\% de los recursos dirigidos a programas sociales se destinan a

\subsection{Evaluación de la política de recursos naturales: política forestal}

El Perú cuenta con un elevado potencial de recursos productivos y con características geoeconómicas únicas que le proporcionan ventajas naturales para la explotación y el comercio de variedades y calidades de productos transables de elevados estándares internacionales. A la consistencia de las políticas de estabilización (control inflacionario, disciplina fiscal y monetaria, regulación con reglas de mercado) se han añadido resultados comerciales significativos: desde 1979 y 1990 no se registraba un saldo de exportaciones netas favorable al país (1,2 por ciento del PBI en el 2004). Esto se ha logrado como consecuencia de las condiciones ventajosas en el mercado mundial de materias primas, así como por el esfuerzo inversor del sector privado y la labor promocional de instituciones públicas (Ministerio de Comercio Exterior, ProInversión, PromPerú) y agentes privados (Asociación de Exportadores, Sociedad Nacional de Industrias, Sociedad de Minería, etcétera). En los últimos años las exportaciones de bienes se incrementaron notablemente, no sólo de recursos primarios (minería, pesca, agricultura), sino también de productos naturales con alto valor agregado, principalmente agroindustriales, lo que delinea una senda de crecimiento sostenidamente alto para el mediano y largo plazo, proceso en el que parti-

gastos administrativos; por otro lado, encuentra que 826 mil beneficiarios de un total de 3 millones son infiltrados en los programas sociales. Un plan de lucha contra la pobreza extrema pasa por elaborar un padrón adecuado de beneficiarios y, de persistir la ineficacia de los gestores públicos, por la tercerización de los programas. 
cipan cerca de cuatro mil empresas, de las cuales la mayoría son nuevas empresas exportadoras de una gama amplia de productos (más de 400 partidas).

En particular, es importante recrear los temas de política pública en el ámbito del fomento de la explotación sostenible de los recursos forestales, de escaso interés público a pesar de su elevadísimo potencial económico. Ello fortalecería la capacidad productiva y exportadora de nuestra economía en el largo plazo.

El Perú posee una superficie de 71,8 millones de hectáreas de bosques naturales, lo que equivale al $56 \%$ del territorio nacional. La superficie apta para la extracción de madera es de 24,5 millones de hectáreas, además hay cerca de 7,5 millones de tierras aptas para la reforestación. Sin embargo, el nuestro es el único país de América Latina y del mundo que no ha desarrollado plantaciones forestales eficientes y competitivas.
La balanza forestal del Perú es deficitaria: importa 270 millones de dólares por año y exporta apenas 140 millones de dólares (el 100\% de bosques tropicales). A la fecha se ha deforestado 8,3 millones de hectáreas, de las cuales 4,7 millones son áreas libres y 3,6 millones son áreas ocupadas $^{6}$.

Brasil cuenta con 5 millones de hectáreas para productos procesados y materia prima para exportación y exporta 6600 millones de dólares por año, de los cuales 5600 provienen de plantaciones forestales. Chile cuenta con 2 millones de hectárea para productos procesados $\mathrm{y}$ materias primas de exportación y alcanza a exportar 3 mil millones de dólares al año. Perú, a pesar de contar con 10,5 millones de hectáreas aptas para plantaciones, exporta 0 dólares. Esto quiere decir que el Perú no aprovecha los bosques de reforestación o no hace uso del esquema de producción de madera en base a plantaciones, como la gran mayo-

Cuadro 3. Comparación del Perú y Chile en recursos, industria y comercio forestal

\begin{tabular}{lrr}
\hline & Perú & Chile \\
\hline Bosques naturales (mill. ha). & 71,8 & 13,8 \\
Áreas reforestadas (mill. ha). & 0,74 & 2,0 \\
Madera industrial (mill. m³) & 1,0 & 27,0 \\
Exportaciones (mill. US\$) & 136 & 2301 \\
Balanza comercial (mill. US\$) & -121 & 1170 \\
Acuerdo comercial con EE. UU. & No & Sí \\
Acuerdo comercial con la Unión Europea & No & Sí \\
Acuerdo comercial con Corea & No & Sí \\
\hline
\end{tabular}

Fuente: Penny Bidegaray, 2005.

6. Cifras proporcionadas por el ingeniero Enrique Toledo (2005), director ejecutivo de Fondebosques, agencia privada promotora de la inver- sión en concesiones forestales en nuestro país desde hace más de dos años. 
ría de países exportadores de esta materia prima lo hace, sólo explota bosques tropicales, degradándolos.

Nuestro país cuenta con ciertas ventajas: mayores rendimientos (20 a $50 \mathrm{~m}^{3}$ / ha/año); turnos de cosecha cortos (ciclo comercial), de 12 a 15 años para aserrío en selva, con eucalipto, y de 7 a 8 años para pulpa, en costa; bajos costos de las tierras (entre 100 y 300 dólares la hectárea); mano de obra abundante; y ubicación estratégica para captar mercados externos. Está demostrado que la explotación dirigida de recursos eleva el valor de la madera, desde 5 dólares hasta 130 dólares. En los mercados de Suecia y Holanda, las sillas para jardín se venden a 78 dólares, mientras las mesas alcanzan 118 dólares; y en el mercado de Estados Unidos, el Lam Parquet cuesta entre 1000 y 1200 dólares el $\mathrm{m}^{3}$. Sin embargo, nuestro país sigue postergando proyectos de inversión en plantaciones forestales que, de cristalizarse, generarían una enorme riqueza y empleo para la población. En el Brasil, las plantaciones forestales comerciales dan ocupación a dos millones de personas, y en Chile han creado 400 mil empleos directos.

De acuerdo con los estudios disponibles, Fondebosques considera que el Perú cuenta con un potencial exportador de 3500 millones de dólares en productos forestales que pueden dirigirse a China, Japón, Taiwán y Corea. Para ello se requiere implementar una estrategia corporativa de promoción de las inversiones y desarrollo de negocios forestales, que incluya capacitación, transferencia tecnológica y promoción de los servicios ambientales del bosque. El objetivo es promover un stock de inversión de 600 millones de dólares a través de la forma- ción de centros de promoción de negocios forestales ${ }^{7}$.

Las actividades promocionales más sólidas a favor de nuestra industria forestal se han originado en iniciativas de grupos empresariales privados organizados. Fondebosques, a través del Sistema Nacional de Negocios Forestales, ha captado el interés de empresas canadienses y ha contribuido a establecer joint ventures entre Forestco GTH Inc. (Canadá) y la Alianza Tambopata (concesionarios de Madre de Dios). Forestco GTH Inc. es una renombrada empresa altamente especializada en planeamiento forestal, manejo y procesamiento de madera dura.

\section{Las nuevas políticas públicas en el Perú}

\subsection{La política de promoción de la innovación y el desarrollo tecnológico}

El crecimiento económico de un país está estrechamente relacionado con su dota-

7. No podemos dejar de mencionar que, hace algunos años, un consorcio privado suizo ofreció al gobierno peruano la posibilidad de desarrollar una inversión por 600 millones de dólares. La oportunidad se perdió y la inversión se hizo en Chile. Recordemos que la naturaleza no ha dotado a Chile con bosques tropicales, pero este país ha logrado desarrollar (con base en plantaciones) una industria forestal generadora de alto valor agregado. Mientras en 1975 exportaba 18 millones de dólares, en el 2004 exportó más de 3 mil millones de dólares, y esta industria da ocupación directa a más de 400 mil trabajadore (Mario Fuito, de la institución Patrimonio Forestas). Igualmente, en el año 2003 una comisión comercial italiana manifestó interés en la producción maderera en el Perú con una propuesta global de inversión estimada en 600 millones de dólares, propuesta que tampoco cristalizó. 
ción de factores productivos (capital, trabajo y recursos naturales) y con la innovación, entendida esta última como el proceso de incorporación de los conocimientos a la producción. Para los economistas, el tema no es nuevo. Desde los economistas clásicos hasta los más modernos han planteado este vínculo. Adam Smith estableció un sistema relacional entre la riqueza de una nación, la división del trabajo y la productividad laboral (al que se suman las condiciones adecuadas de mercado y de las instituciones); David Ricardo aportó la teoría de los rendimientos decrecientes de las tierras; Carlos Marx planteó el concepto explicativo clave de su ley del decrecimiento de la ganancia en el largo plazo: el impacto de la mayor composición orgánica del capital; Joseph Schumpeter sostuvo que la innovación determina el crecimiento a largo plazo y se hizo conocido por sus teorías de la destrucción creativa y de la acumulación creadora (ya explicadas en la primera sección). A esta tradición analítica de la innovación añadimos la prolífica corriente de diseño de modelos de crecimiento que incorporan el cambio tecnológico como variable endógena. En el documento Desarrollo productivo en economías abiertas, la Cepal sostiene:

En la medida en que la tecnología determina la productividad potencial del conjunto de los factores y, por lo tanto, la competitividad de las empresas, el ritmo de innovación constituye el vehículo mediante el cual el bienestar de un país se aproxima o se aparta del imperante en las áreas más desarrolladas del planeta, que pueden considerarse en la frontera tecnológica mundial o cercanas a ella (Cepal, 2004: 211).

Esta disyuntiva estratégica también ha sido demostrada por investigadores del
Banco Mundial (De Ferranti y otros, 2002) en su ensayo De los recursos naturales a la economía del conocimiento. Trabajando con un gran número de países y con el periodo 1976-1999, ellos demuestran que existe una estrecha relación $(\mathrm{R}=0,62)$ entre producto y conocimiento, relación que se hace aun mayor cuando se correlacionan los índices de tecnología de la información y las comunicaciones (TIC) con el PBI per cápita. Estos son factores clave del nivel de desarrollo de las naciones y de las diferencias en su desempeño comercial en el nuevo escenario mundial.

La innovación y el aprendizaje constituyen los esfuerzos de las empresas por aplicar, perfeccionar y desarrollar in contínuum nuevas tecnologías de producción y mejores prácticas de gestión. Estos esfuerzos pueden ser entendidos como un complejo proceso colectivo de incorporación de nuevos métodos de producción. Se trata de un proceso sistémico en el que participan una serie de agentes (empresas, institutos públicos de investigación y tecnología, instituciones académicas y entidades financieras) cuya interrelación en torno a la transmisión de conocimientos y su aplicación a la producción dentro de un país se denomina sistema nacional de innovación.

El desarrollo productivo de las economías que se proponen reducir la brecha de productividad con las más avanzadas exige la adopción de políticas públicas destinadas a crear y desarrollar capacidades de innovación que permitan aprovechar las ventajas de la aceleración del cambio tecnológico y de la apertura económica. Para seguir elevando la productividad y beneficiarse en mayor medida de la importación de tecnología, resulta imprescindible crear un marco más propicio a los esfuer- 
zos de constituir capacidades endógenas de innovación (Cepal, 2004: 213).

El fortalecimiento permanente de estas capacidades es una condición para mantener la competitividad de las empresas, la que a su vez constituye el soporte del crecimiento sostenido de la economía en el largo plazo (Cepal, 2004: 211). Este es el objetivo de la política pública que ofrece la posibilidad de fomentar las capacidades endógenas de innovación.

Veamos algunas experiencias. Las naciones que tienen una sólida cultura estratégica y una muy clara ruta de desarrollo mantienen altas tasas de inversión en innovación tecnológica, entre $2,5 \%$ y $3 \%$ del PBI, mientras el Perú apenas llega al 0,11\% del PBI. Costa Rica -para no insistir en la incómoda comparación con el modelo de crecimiento económico chileno- ha puesto en marcha una peculiar política de vinculación de las políticas tecnológicas con las tasas de fomento de las exportaciones. Cuenta con experiencia en el ejercicio de un conjunto de políticas de ciencia y tecnología en las que se combinan subsidios con la adopción de normas de calidad, fomento de la capacitación de recursos humanos y mayor colaboración entre los centros de investigación y las empresas de los sectores exportadores (Cepal, 2004: 219). No es casual que en dicho país radique la central de fabricación de microprocesadores Intel, el ícono de la tecnología más dinámica del mundo. Brasil, por su parte, es el único país en América Latina que destina casi un punto porcentual de su PBI al esfuerzo de investigación y desarrollo; a ello le añade una política de fomento de la educación superior a nivel de posgrado, para lo cual presupuesta el equivalente al $0,25 \%$ del PBI cada año.
De otro lado, el sector empresarial corporativo en muchas naciones compromete generalmente entre el $10 \%$ y el $20 \%$ de sus ingresos a actividades de investigación y desarrollo (I \& D $)^{8}$. En el Perú, hay muy pocos referentes de iniciativas de esta naturaleza, tanto del Estado como del sector empresarial; las escasas experiencias se encuentran en las corporaciones extranjeras dedicadas a la explotación de recursos naturales. Dada la poca información disponible, está pendiente el estudio de este tema en nuestro país. Sin embargo, a la luz de las experiencias exitosas de países como Colombia, Chile y Costa Rica -por ejemplo-, en materia de fomento de la innovación y el desarrollo tecnológico, podemos establecer algunas líneas de política para el Perú.

A partir de los años noventa, Chile y Costa Rica se han constituido en principales referentes al pasar de un modelo de oferta a un modelo de demanda, lo que significa poner énfasis en los incentivos del mercado y en la demanda del sector productivo. Argentina emplea algunos instrumentos para facilitar la prestación de servicios y el desarrollo tecnológico de las pymes. El instrumento ad hoc creado se denomina Fondo Tecnológico Argentino (Fontar), que otorga aportes no reembolsables, créditos y subsidios sobre la base de subastas públicas. En Chile, el cambio más importante proviene del mecanismo de gestión de los fondos para las pymes a través de los Proyectos de Fomento (Profo), el Fondo de Asistencia Técnica (FAT) y el Fondo de Fomento al Desarrollo Científico y Tecno-

8. Exceptuando a Australia y España, en los países desarrollados las empresas invierten entre 200 y 700 dólares por habitante; y el Estado, entre 150 y 250 dólares por habitante. 
lógico (Fondep), que están apoyando la reestructuración tecnológica y el reforzamiento de las estrategias empresariales orientadas hacia el exterior.

Los fondos tecnológicos son la novedad en materia de política de ciencia y tecnología implementada recientemente en América Latina. En Argentina, Chile, Colombia, Costa Rica y México se desarrollan mecanismos de subsidio sobre la base de la demanda, en tanto que en Brasil se aplica una combinación de modelos de oferta y demanda, haciendo partícipes del esfuerzo científico y tecnológico a instituciones académicas y centros de investigación (oferta) y a empresas (demanda).

En el Perú persiste el tradicional enfoque de oferta, que descansa fundamentalmente en el esfuerzo de los centros productores de tecnología, como un segmento estanco y débil básicamente público y sin vínculos de coordinación con el sector privado. El sector privado, por su parte, ha adquirido una dinámica propia, distante de los ámbitos públicos y más relacionada con las proyecciones del mercado internacional y con las necesidades de adaptación tecnológica a las exigencias de este.

Al respecto, cabe señalar que debido a que el Perú es uno de los países más ricos en plantas domesticadas del mundo, en 1996 se estableció el registro nacional de variedades vegetales. Sin embargo, a pesar del enorme esfuerzo de innovación al interior de las empresas y entre los pro-

9. Claudia Fernandini, del Estudio Clarke, Modet \& Co., sostiene que es una situación absolutamente paradójica en proporción al rico acervo de variedades con que cuenta nuestro país y con pios agricultores, desde entonces apenas se han presentado 60 solicitudes de incorporación a este registro ${ }^{9}$. Más aun, de los 11 títulos otorgados, únicamente 9 permanecen vigentes. Como sabemos, tales registros reciben el nombre técnico de variedades vegetales, que es la figura legal que protege la innovación desarrollada por empresas o asociaciones y la propiedad privada. Dicha variedad puede poseer alguna característica comercial valiosa, como ser resistente a una plaga o tener un color especial atractivo para el mercado. Los escasos registros han sido efectuados mayormente por empresas agroexportadoras: dos corresponden a variedades de marigold de la empresa Agrícola Barranca (Agrobasa); y cuatro, a variedades de arroz de propiedad, respectivamente, de la Cía. Arrocera del Perú, del New Zeland Institute for Crop \& Food Research, y dos de la empresa Danziger Dan Flower Farms.

\subsection{La política promotora del desarrollo empresarial y los sistemas de encadenamientos productivos}

El número, el potencial y la calidad de los agentes productivos constituyen también factores determinantes para el desarrollo económico de un país. La «empresarialidad» es una dimensión cualitativa, propia del concepto de capital intangible, y comprende una serie de características del tejido empresarial de un país: espíritu, vocación, creación, consolidación y calidad. Es una mentalidad económica, un ethos económico que fuera estudiado por Max Weber (1904-1905) para señalar el

relación a los 25 títulos vigentes en Bolivia, 159 en Ecuador y 1174 en Argentina, según cifras del 2003. 
«espíritu capitalista entendido como una concepción de ética de trabajo para la vida cotidiana del capitalismo» ${ }^{10}$. Entonces, el concepto de empresarialidad a la que hacemos referencia comprende un sinnúmero de elementos vinculados con la trayectoria histórica de una sociedad; son factores sociales, educativos, culturales y económicos.

Para incorporar en la agenda de los poderes del Estado la política de fortalecimiento y articulación empresarial, se deben tomar en consideración los siguientes elementos. Primero, la constatación de que el liderazgo empresarial reside en las empresas más grandes y en los grupos económicos consolidados; es vital para la política pública peruana identificar las fuentes del liderazgo y promoverlo o fortalecerlo si es incipiente y débil. Segundo, en esa misma dirección, el Estado debe apuntar a la profundización del proceso emprendedor que nace con la dinámica de creación de pequeñas empresas y de renovación de las existentes en un nuevo contexto de competitividad internacional; no debe hacerlo con sentido asistencialista, sino con criterio de formación de nuevas empresas emprendedoras, las que en su momento Joseph Schumpeter (1911: 134) calificara como el motor de la innovación capitalista en su etapa temprana de crecimiento histórico. Y en tercer lugar, el fomento de los sistemas de encadenamientos productivos, de articulación económica, comercial y territorial de grandes, medianas y pequeñas empresas productoras, teniendo como ancla real de dicha articulación la producción de bienes de ele-

10. Nos referimos a su centenaria obra: La ética protestante y el espíritu del capitalismo, recientemente editada en forma completa por el Fondo de Cultura Económica. vadas ventajas internacionales. El Perú sí cuenta con innumerables ventajas de este tipo para la formación de «distritos industriales», concebidos hace más de un siglo por Alfred Marshall.

\subsubsection{El conglomerado empresarial: la teoría}

De acuerdo con los cánones generalmente aceptados por la teoría económica, en el campo de las organizaciones empresariales hay una tipología que las clasifica en:

a) La gran empresa o corporación, la gran compañía establecida que se caracteriza por la combinación de tecnología avanzada, uso masivo del capital, organización compleja y planificación.

b) La empresa emprendedora y competitiva, que es el resultado de la determinación y persistencia de los individuos por poner en marcha una empresa propia.

c) Las nuevas empresas «marginales», en su gran mayoría pequeños negocios con escasas posibilidades de alcanzar un tamaño o una rentabilidad significativos.

d) Las nuevas empresas financiadas con capital de riesgo, que combinan las cualidades de la empresa emprendedora con el financiamiento corporativo.

e) Las empresas «revolucionarias» $\mathrm{O}$ «gacelas», las cuales implican un alto grado de innovación en gran escala.

Las corporaciones ejercen el liderazgo empresarial en las sociedades industriales maduras y en desarrollo; su paradigma tiene larga data y un complejo soporte académico Alfred Chandler (1990) ${ }^{11}$

11. En su obra Scale and scope, the dynamics of industrial capitalism (Cambridge, Mass.: Belk- 
se refiere a ellas en los siguientes términos:

En la segunda mitad del siglo XIX hizo su aparición una nueva forma de capitalismo: la gran empresa de negocios de índole administrativa. Esta nueva modalidad controlada por una jerarquía de ejecutivos asalariados en sustitución de los propietarios, 'se impuso en las industrias básicas de Estados Unidos' hacia fines de la Primera Guerra Mundial. Y en la década de 1960 ya se había generalizado.

Igualmente, John Kenneth Galbraith ${ }^{12}$, en su obra El nuevo estado industrial, observó que las 500 más grandes corporaciones estadounidenses (corporations) producían casi la mitad de los bienes y servicios anualmente disponibles en ese país.

Hace setenta años la sociedad mercantil era el instrumento de sus propietarios y una proyección de sus personalidades. Carnegie, Rockefeller, Arriman, Mellon, Guggenheim, Ford. Los hombres que dirigen hoy las grandes compañías no poseen ninguna parte social considerable de las empresas. (Galbraith, 1967: 18; el resaltado es nuestro).

La inteligencia organizada... Este nuevo factor es la asociación de hombres de diversos conocimientos técnicos, experiencias o demás talentos requeridos por la

nap Press, 1990). Este notable economista también es conocido por sus obras Strategy and structure (MIT Press, 1962) y La mano visible (Harvard University Press. 1977).

12. Famoso y prestigiado economista norteamericano, escribió una decena de publicaciones importantes, entre las cuales se cuentan: El dinero, Capitalismo americano, La sociedad opulenta (1960), La hora liberal, La economía y el arte de la controversia, Viaje a Polonia y Yugoslavia, El desarrollo económico en perspectiva, entre otras. tecnología industrial y la planificación modernas. (Ídem: 77).

El éxito de la empresa moderna depende de la eficacia de esta organización... (Ídem: 78).

Joseph Schumpeter (1911) había previsto como inevitable el surgimiento de las grandes corporaciones y pronosticado que ese hecho sería la ruina del capitalismo, pues ahogaría la «energía innovadora» del emprendedor individual.

La gigantesca unidad industrial completamente burocratizada no sólo reemplaza la pequeña o mediana empresa y expropia a sus propietarios, sino que en definitiva también reemplaza al emprendedor y expropia a la burguesía como clase, la cual perderá por efecto de ello no sólo su ingreso, sino también, lo cual es infinitamente más importante, su función (Schumpeter, 1911: 134).

Frank Knight, contemporáneo de Schumpeter, consideraba que los administradores que no poseían una participación significativa en la propiedad de la empresa tenderían a ser mucho más conservadores y a mostrar mayor aversión al riesgo que los emprendedores fundadores.

Con el tiempo, las gigantescas unidades industriales completamente burocratizadas de Schumpeter se constituyeron en «una dinámica o fuerza de cambio fundamental en las economías capitalistas», transformación que "produciría el más rápido crecimiento económico en la historia de la humanidad». En comparación con lo que William Baumol llama los desordenados procesos de decisión del emprendedor individual, las iniciativas corporativas rutinarias son las que ofrecen mayores oportunidades de examen sistemático. 


\subsubsection{El concepto de emprendedores de nuevas empresas}

Si bien la teoría económica se ha ocupado principalmente de la gran empresa, muy recientemente ha logrado constituir un sólido marco analítico de la dinámica empresarial, es decir, de la relación temporal entre emprendimiento y organizaciones corporativas. El renovado interés por la capacidad de los emprendedores se inicia en 1980.

La capacidad de los emprendedores es un concepto aún en busca de significado en el sentido académico. Según Amar V. Bhidé (2001), emprendedores son los individuos que ponen en marcha una empresa propia y cumplen las funciones de coordinación, arbitraje, innovación e incertidumbre. En el caso peruano, Santiago Roca define las empresas pequeñas y microempresas emprendedoras, identificadas en el mundo empresarial como mypes, en los siguientes términos:

[Son] un agente promotor de eficiencia económica, innovación constante, exportación no tradicional (de alto valor agregado) y núcleo de la ventaja competitiva futura. Esta es la visión competitiva de las nuevas empresas en el Perú. (Roca y colab., 2002: 593-605).

Una de las características más obvias de las empresas emprendedoras es la baja escala que requieren para operar de manera rentable. El factor determinante y el que las distingue de las marginales es la incertidumbre -derivada de la turbulencia del mercado y de la dependencia de las empresas respecto al esfuerzo de sus propietarios-. El rendimiento objetivo calculado del inicio de una empresa promisoria suele ser de tan bajo valor como el de una empresa marginal. No obstante, la incertidumbre introduce un sesgo en la distribución de ganancias y crea una modesta posibilidad de que el emprendedor reciba un alto rendimiento.

\subsubsection{El proceso dinámico de emprendedores a corporaciones}

En la representación esquemática de la evolución de las empresas emprendedoras a corporaciones, es decir, en el proceso de transformación exitosa de las empresas promisorias (Figura 4) se puede definir las siguientes variables asociadas al tiempo:

a) La inversión inicial. Es el compromiso irreversible de fondos, tiempo, prestigio $\mathrm{u}$ otros recursos por parte del individuo o empresa ejecutora de la iniciativa con la intención de obtener un rendimiento.

b) La incertidumbre. Conforme a Frank Knight, es un riesgo inconmensurable e incuantificable. Los emprendedores que acometen iniciativas inciertas enfrentan un espectro entre resultados deseables e indeseables, pero no pueden cuantificar sus probabilidades ni prever por completo los posibles resultados. La incertidumbre es irreductible en la medida en que no puede atenuarse mediante prueba o investigación previas, sin la efectiva puesta en práctica de la iniciativa ${ }^{13}$.

13. Según Darcy Fuenzalida, director de la Escuela Internacional de Gestión Empresarial: «Una de las labores fundamentales del empresario es saber adecuarse a las realidades que le impone el medio; esto denota la capacidad de gestión que él desarrolla. Siempre nos vamos a enfren- 


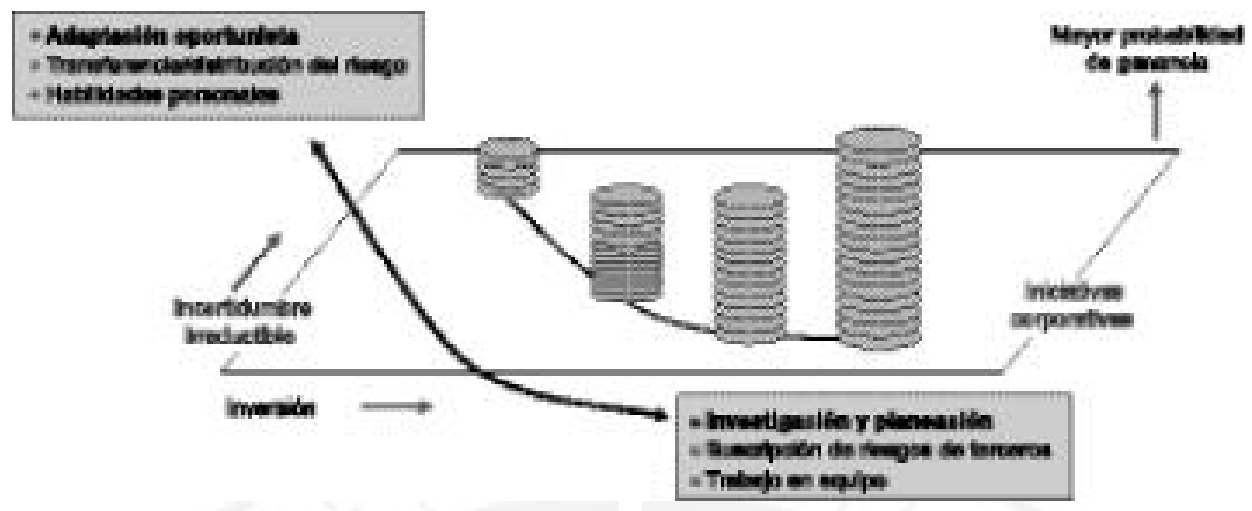

Fuente: Amar V. Bhidé, 2001.

Figura 4

Diagrama inversión, incertidumbre y ganancia

c) La ganancia probable. Es la mejor conjetura objetiva posible acerca del valor de los flujos de efectivo que se espera generar con la ejecución de una iniciativa.

En la etapa de surgimiento, los emprendedores ejecutan proyectos sumamente inciertos que no requieren una abultada inversión inicial y que improbablemente generarán grandes utilidades (Bhidé, 2001). Con el afán de crecer, estos emprendedores invierten después en proyectos más grandes y relativamente menos inciertos.

Cuando estas compañías llegan a la madurez, se centran en iniciativas que su-

tar a condiciones adversas, de menor o mayor magnitud y de distinto origen, por eso el empresario exitoso es aquel que tiene mayor capacidad de adaptación, de propensión al cambio y que está mirando en el largo plazo la forma de desarrollar su negocio dentro de las condiciones que imperan» (Entrevista en $\mathrm{El}$ Comercio. Lima, 22 de mar., 2004, pág. B2). ponen una significativa inversión inicial -con utilidades esperadas proporcionalmente cuantiosas- y una incertidumbre relativamente baja. Inicialmente, sujetos a significativas restricciones de capital así como a un alto grado de incertidumbre, los fundadores de nuevas empresas confían en la adaptación oportunista a sucesos inesperados. Cuando las empresas crecen y comprometen más recursos en iniciativas menos inciertas (es decir, con riesgos y rendimientos más definidos), el oportunismo da paso a intentos sistemáticos de previsión y planeación de largo plazo (ver nuevamente la figura 4).

El origen de casi todas las nuevas empresas es la búsqueda de autoempleo, no la intención expresa de desarrollar nuevos productos, mercados, tecnologías, etcétera. En 1992, por ejemplo, alrededor de 21 millones de empresas declararon impuestos en Estados Unidos de América. De ese total, 71\% correspondió a propietarios individuales, sólo $4 \%$ de los cuales reportaron ingresos brutos superiores a 1 millón 
de dólares. Así, todo indica que lo más común es que la pequeña empresa permanezca como tal a lo largo de su existencia. Y si bien en los últimos 25 años la pequeña empresa ha generado dos terceras partes del empleo neto en el sector privado estadounidense, ello fue obra de apenas unas cuantas compañías de rápido crecimiento. Algunos autores han estimado que las empresas «gacelas», aproximadamente 350 mil entre 1988 y 1992, generaron el $60 \%$ de los nuevos empleos creados en la economía de Estados Unidos de América (Bhidé, 2001).

\subsubsection{Los grupos empresariales tradicionales en el Perú}

Los grupos representativos de las corporaciones de origen nacional son el Grupo Brescia y el Grupo Romero, ambos han desarrollado una red de empresas integradas por procesos verticales y horizontales -productivos y financieros- de larga data, el primero desde 1889 y el segundo desde 1880.

El tiempo y la diversificación han tenido un rol preponderante en la gran envergadura de los negocios que actualmente poseen estos grupos. Romero y Brescia invirtieron en comercio, agricultura, pesca, industria y en el sector financiero en un proceso que tomó no menos de 50 años antes de lograr consolidarse. El trabajo nunca fue fácil; aplicaron esfuerzo y habilidad para crecer. Calixto Romero, el fundador del grupo que lleva su apellido, fue un comerciante que sacó provecho de un sector agroindustrial piurano que carecía de fuentes de financiamiento. Prestaba dinero y, queriéndolo o no, se quedaba con las tierras de quienes no le pagaban. Fortunato Brescia, el otro fundador, era un agricultor pequeño que adquirió terrenos en las afueras de Lima. Quería estar cerca de la ciudad a la que proveía de panllevar, sin imaginar que las chacras que compró adquirirían gran valor cuando la ciudad comenzó a expandirse. Hoy el Grupo Romero tiene la propiedad y el control mayoritarios de las corporaciones Banco de Crédito del Perú y Alicorp, entre las más importantes, mientras los Brescia mantienen con discreción el control de grandes corporaciones. La más reciente noticia relacionada con ellos fue la venta de su participación en Backus al Grupo Bavaria por 420 millones de dólares (Marticorena, 2005).

\subsubsection{Los grupos emergentes en el Perú}

A diferencia de los grupos tradicionales, el crecimiento de los empresarios emergentes ha sido más acelerado, con diversificación mínima, gastos administrativos austeros y haciendo de la especialización una virtud. Según Miguel Ferré, profesor del PAD de la Universidad de Piura, hay algo en común en los empresarios emergentes: amasan fortunas tras «encontrar su oportunidad en la base de la pirámide (sectores C y D), ignorada por los grupos empresariales tradicionales». Es la misma estrategia de posicionamiento que ha logrado el Grupo Añaños (Ajegroup) en su exitosa aventura empresarial en México.

Una diferencia notable en materia de estrategia de crecimiento es que los grupos tradicionales se diversificaron a través de la fusión (los que no lo hicieron quebraron), mientras los grupos emergentes, que son los surgidos en los últimos 25 años, buscan las oportunidades de negocios en el exterior. La expansión de Ajegroup a Ecuador, Venezuela, México, 
Costa Rica, está siendo seguida por Topy Top (por la maquila en textiles) y los Perales Huancaruna (Inversiones Altomayo).

Destaquemos otro elemento de importancia para el diseño y monitoreo de una política de fomento empresarial y de emprendimiento promovida por el Estado: Muchos componentes de las fortunas de los grupos tradicionales deben haberse originado en factores políticos, sobre todo en el periodo militar de los años setenta, cuando estos empresarios eran considerados por algunos sectores de la política nacional como los grupos privados con visión de progreso ${ }^{14}$. Estos se mimetizan entre los canales formales de las relaciones sociales, institucionales y hasta de política internacional para desarrollar ventajas de negocios, con beneplácito de las autoridades. En cambio, los emergentes, de la era de la globalización y de la apertura económica, son desafectos a la política: simplemente apuestan por la estabilidad en las reglas de juego y las condiciones institucionales de los mercados libres en los que se desenvuelven exitosamente. Son negocios de familias empresarias - no de una empresa familiar- de gran sentido profesional, visión de los negocios internacionales y experiencia, que están asimilando con éxito ${ }^{15}$.

14. Francisco Durand (2004) habla de la clase dominante y no de la clase dirigente, que es la acepción más cercana a la caracterización de un sector social vinculado a los procesos políticos.

15. Otros grupos empresariales emergentes que han logrado consolidarse como empresas corporativas son el Grupo Anypsa (de la familia Torvisco), Intradevco S.A. (de Rafael Arosemena) y Trading Fashion Line (Topy Top, de la familia Flores) (ver Día_1, El Comercio. Lima, set. 2004.

\subsubsection{Los encadenamientos productivos en el Perú}

Se denomina cadena productiva al conjunto de agentes y actividades económicas que intervienen en un proceso productivo, desde la provisión de insumos y materias primas hasta la comercialización de los productos en los mercados internos y externos, pasando, obviamente, por la transformación y producción de bienes intermedios y finales.

El objetivo de este tipo de articulaciones económico-financiero-territoriales del esfuerzo empresarial privado consiste en hacer posible los aumentos colectivos de eficiencia y productividad, beneficiándose de las economías de escala y de la aglomeración que estos procesos generan.

La estimulación de las sinergias y externalidades positivas resultantes pasan por la predisposición del factor crítico: el factor «empresarial», el que puede determinar las posibilidades de consolidación de las cadenas productivas, su articulación con empresas grandes, su inserción internacional y la dinámica tecnológica del colectivo productivo, como se ha comprobado en otras latitudes: Japón, Asia del Pacífico, Estados Unidos e Irlanda.

En nuestro país, es muy reciente la experiencia sobre el diseño y ejecución de políticas de articulación productiva. En el ámbito sectorial, sin embargo, debemos hacer mención al esfuerzo público por fomentar las denominadas cadenas productivas en la agroindustria, en el marco de la Comunidad Andina de Naciones (CAN). Para promover el desarrollo de este sector, se han formado grupos ad hoc por tipo de cadenas agroindustriales, integrados por representantes de los productores agrí- 
colas, de la agroindustria y del gobierno. Hasta ahora se han constituido grupos para los siguientes productos: arroz, azúcar, cereales, forrajes -alimentos balanceadosavicultura y cereales de consumo humano. Se proyecta formar la aglomeración del café y se está avanzando con las oleaginosas (la cadena productiva de la palma aceitera).

Sin embargo, en nuestro país se observan dos problemas medulares: en primer lugar, que se sigue conceptualizando las cadenas productivas como simples procesos de articulación de agentes en torno a los procesos operacionales del producto, y no como cadena institucional de valor nucleada en aglomeraciones empresariales especializadas; en segundo lugar, que la burocracia estatal es poco receptiva a nociones de rentabilidad y retornos sobre el capital.

Veamos algunas experiencias internacionales exitosas en América Latina. Costa Rica, con un territorio más pequeño que el departamento de Arequipa y con 1,8 millones de hectáreas de bosques, de los cuales casi el $70 \%$ se encuentra protegido, ha desarrollado ecoturismo y generado 1690 millones de dólares anuales (Galarza, 2003). Y al igual que la mayoría de países centroamericanos, viene impulsando un sistema de industrialización para la exportación no excluyente, explotando sus ventajas naturales de localización respecto al mercado más grande del mundo, a partir de la constitución de sendas industrias de maquila en gran número de partidas industriales nuevas, incluidas las relacionadas con la informática y la producción textil. Colombia cuenta con un modelo de cluster productivo exitoso que exhibir: la cadena productiva del azúcar en el Valle del Cauca. Chile da ejemplo con el cluster del salmón, que en su fase de aprendizaje, hace 25 años atrás, apenas alcanzaba un volumen de exportación de hasta 900 toneladas a un precio aproximado de 10 dólares por kilogramo. Ahora, en su fase de consolidación como el segundo exportador del mundo después de Noruega, la industria del salmón tiene capacidad para venderle al mundo hasta 400 mil toneladas y a un precio que varía entre 2,9 y 4,5 dólares por kilo. El Perú cuenta con el cluster de la alpaca y está en capacidad de desarrollar muchas cadenas agroindustriales similares, como hemos señalado antes.

\subsubsection{Las condiciones microeconómi- cas y macroeconómicas favorables al fomento de la articulación empresa- rial, del emprendimiento empresarial y de la competitividad}

La teoría macroeconómica formula un modelo virtuoso de interrelación entre el stock de capital, la tasa de producción, el nivel de ahorro-inversión, y la mayor inversión inducida. Los esfuerzos sociales por promover el cambio tecnológico, la solución del problema sistémico del empleo productivo y la reconversión del capital humano deben ser adecuadamente canalizados por el Estado.

A pesar de que en muchos pasajes de este estudio se ha constatado que el Perú no aprovecha adecuadamente sus recursos naturales y humanos, parece ser que se está vislumbrando, al menos en el papel, una estrategia nacional de desarrollo.

En julio del 2005, el Gobierno presentó el llamado Plan Nacional de Competitividad (PNC), que ya está en su primera fase de implementación, de acuerdo con las metas de cumplimiento en el corto 
Cuadro 4. Principales áreas de acción del plan nacional de competitividad

\begin{tabular}{|c|c|c|}
\hline Área & Meta/año & Acciones \\
\hline \multirow{4}{*}{ Infraestructura } & 2006 & $\begin{array}{l}\text { Lograr la participación del sector privado en el puerto } \\
\text { del Callao. }\end{array}$ \\
\hline & 2006 & $\begin{array}{l}\text { Disminuir en } 10 \% \text { el número de accidentes viales y en } \\
80 \% \text { para el } 2008 \text {. }\end{array}$ \\
\hline & 2006 & $\begin{array}{l}\text { Habilitar espacios para la expansión del aeropuerto } \\
\text { internacional Jorge Chávez. }\end{array}$ \\
\hline & 2007 & $\begin{array}{l}\text { Crear salas especializadas en asuntos regulatorios y } \\
\text { permitir el arbitraje. }\end{array}$ \\
\hline \multirow{3}{*}{$\begin{array}{l}\text { Innovación } \\
\text { tecnológica e } \\
\text { innovación } \\
\text { empresarial }\end{array}$} & 2006 & $\begin{array}{l}\text { Incrementar en } 20 \% \text { los proyectos de transferencia } \\
\text { tecnológica para mejorar la producción. }\end{array}$ \\
\hline & 2006 & $\begin{array}{l}\text { Iniciar estudios para formación de incubadoras o } \\
\text { promotoras de empresas. }\end{array}$ \\
\hline & 2008 & $\begin{array}{l}\text { Incrementar en } 25 \% \text { la participación de fondos exter- } \\
\text { nos en el presupuesto de investigación universitaria. }\end{array}$ \\
\hline \multirow{5}{*}{$\begin{array}{c}\text { Política } \\
\text { económica, } \\
\text { mercados } \\
\text { financieros y de } \\
\text { capitales }\end{array}$} & 2006 & Racionalizar las exoneraciones y beneficios tributarios. \\
\hline & 2006 & Concluir el estudio para la reforma del Tribunal Fiscal. \\
\hline & 2006 & $\begin{array}{l}\text { Crear incentivos tributarios para programas de } \\
\text { capacitación de trabajadores. }\end{array}$ \\
\hline & 2006 & Instalar y capacitar todos los juzgados comerciales. \\
\hline & 2006 & $\begin{array}{l}\text { Establecer plazo de permanencia de la información en } \\
\text { las centrales de riesgos (hasta } 5 \text { años). }\end{array}$ \\
\hline \multirow{3}{*}{ Educación } & 2011 & $\begin{array}{l}\text { Atender con educación inicial al } 80 \% \text { de la población } \\
\text { entre } 4 \text { y } 5 \text { años. }\end{array}$ \\
\hline & 2005 & Implementar un sistema de evaluación de profesores. \\
\hline & 2006 & $\begin{array}{l}\text { Establecer un sistema de demanda y tendencia del } \\
\text { mercado laboral. }\end{array}$ \\
\hline \multirow{2}{*}{$\begin{array}{l}\text { Articulación } \\
\text { empresarial }\end{array}$} & 2005 & Identificar cadenas productivas y conglomerados. \\
\hline & 2006 & Hacer el seguimiento de su desempeño. \\
\hline \multirow{3}{*}{$\begin{array}{l}\text { Fortalecimiento } \\
\text { institucional }\end{array}$} & 2008 & $\begin{array}{l}\text { Crear en el Congreso una comisión responsable de la } \\
\text { política de competitividad del país. }\end{array}$ \\
\hline & 2008 & $\begin{array}{l}\text { Principales políticas de Estado trascenderán a } \\
\text { cambios de gobierno o de ministros. }\end{array}$ \\
\hline & 2008 & $\begin{array}{l}\text { Reducir en } 50 \% \text { la duración de trámites } \\
\text { administrativos. }\end{array}$ \\
\hline
\end{tabular}

Fuente: Presidencia del Consejo de Ministros, julio 2005. 
plazo (sus lineamientos se muestran en el cuadro 4). Según el ministro de la Producción, el PNC constituye una «agenda interna para la inserción exitosa del Perú en el mercado global».

\subsection{La política de afianzamiento institucional}

Como hemos sostenido en la primera sección, en nuestro país existe un contexto de fragilidad institucional y precariedad política (deslegitimación de los liderazgos y partidos políticos), condiciones en las cuales es poco probable lograr eficiencia en las políticas públicas y alcanzar los objetivos de transformación social y de un Estado cumplidor de su rol; estos dos retos se vuelven muy difíciles de enfrentar. Van más allá de la percepción oficial, como la de las autoridades judiciales, para quienes «El Poder Judicial es esencialmente ineficiente [...] y el problema es universal, la demora de la carga procesal». (Doctor Manuel Sánchez Palacios, ex presidente del Poder Judicial).

Revisemos algunas cifras e ilustraciones de casos. Si utilizamos los indicadores de gobernabilidad del Banco Mundial, el Perú ha logrado indicadores positivos en los índices de participación y responsabilidad y en calidad regulatoria, pero siempre ubicándose por debajo del índice promedio de otros países de la región y del mundo; por el contrario, revela baja calidad institucional si la medimos con los índices de estabilidad política, eficacia del gobierno, Estado de Derecho y con el índice de control de la corrupción (Cepal, 2004).

Cuando los sistemas institucionales manifiestan problemas sistémicos de centralidad y de función gubernamental, co- mo ocurre en nuestro país, las políticas públicas deben ser evaluadas en el contexto de una precariedad política evidente y una informalidad institucional generalizada, que tipifica una forma particular de estructurar políticas públicas en países de frágil institucionalidad. Aquí, el Estado y el gobierno no son capaces de mantener la unidad del poder político institucionalizado, ni la unidad de acción de sus instituciones.

El problema no sólo pasa por implementar una revolución tecnológica en el sector público que sincronice con la reforma del Estado, como comúnmente se cree; exige un sostenido proceso de transformación social y del Estado. Apuntamos al menos tres puntos centrales de la agenda gubernamental pendientes, vinculados al urgente proceso de reforma institucional. Los planteamos como tres dicotomías institucionales: el primero, entre el proceso de descentralización y modernización del Estado, de un lado, y la estrategia de desarrollo, del otro lado; el segundo, entre el proceso participativo de los actores sociales, por un lado, y la crisis política y la deslegitimación de los liderazgos políticos, por el otro; y en tercer lugar, entre la disfuncionalidad entre el modelo de desarrollo de cadenas productivas, por un lado, y la ausencia de articulación entre la oferta y la demanda de las regiones, por otro lado, desbalance este último que debilita el proceso de integración territorial de las organizaciones sociales. Este tema constituye un reto por atenderse en la agenda social.

La reforma del Estado, pendiente de discutirse y aprobarse en el Congreso Nacional, deberá trascender el enfoque de Estado-univectorial, que cambia mecánicamente su orientación en sentido pendu- 
lar y en un plano dimensional -del liberalismo al intervencionismo o viceversa, del Estado Gendarme al Estado de Bienestar-, e ir más allá, esto es, a la formación de un Estado impulsor, con vectores multidimensionales apuntando hacia el progreso colectivo. Este propósito exige una gigantesca fuerza motora que produzca estrategias nacionales y sectoriales, cuadros, líderes, técnicos y profesionales de calidad, instituciones innovadoras, mejores prácticas, cultura, legados, alertas, distintivos, leyes, reglamentaciones, acciones y procesos modelo, etcétera. Esto es propio de un Estado weberiano transformado, el ideal de Estado que en nuestro país no está diseñado aún ${ }^{16}$. Este estudio panorámico no pretende desarrollarlo.

\section{Conclusiones y recomendaciones}

1. Las políticas públicas mantienen su esquema tradicional de planeación y ejecución con altos elementos de ineficiencia.

2. Las nuevas políticas de fomento de la innovación y del desarrollo tecnológico, del desarrollo empresarial y de la estructuración de aglomeraciones de cadenas productivas de alto valor no

16. No debemos dejar pasar por alto que el Acuerdo Nacional ha delineado claramente los elementos fundamentales de las políticas de Estado en materia de derecho y Estado de Derecho, equidad y justicia social, competitividad del país y en cuanto a su transformación en un Estado eficiente, transparente y descentralizado. Sus 31 puntos de agenda son permanentemente evaluados por las organizaciones civiles organizadas (ver: Canadian Internacional Development Agency). cuentan con el soporte institucional suficiente. Sólo se registran en grandes intenciones, como el Plan Nacional de Competitividad, que posiblemente no sea continuado por el gobierno que se elegirá en el 2006.

3. Sobre la política de fortalecimiento institucional, no se ha analizado exhaustivamente, pero las evidencias prueban las buenas intenciones y el alto grado de empoderamiento de las organizaciones civiles, aunque no es un tema prioritario en la agenda pública. La reforma del Estado solamente pretende enfrentar la simplificación administrativa y el establecimiento de la Escuela de Administración Pública, aún cuando estos aspectos ya serían un avance importante.

4. Los actores privados, empresas, organizaciones y ciudadanos son factores determinantes en el proceso de emprendimiento y liderazgo empresarial, así como en el afianzamiento del naciente proceso de constitución de aglomeraciones productivas.

5. En la perspectiva de crecimiento viable y sostenible de nuestra economía en el largo plazo, no existe la dicotomía entre crecimiento basado en recursos naturales, y la tecnología y la «economía del conocimiento». Los recursos naturales (como los forestales) ofrecen tantas posibilidades de progreso tecnológico y aumento de la productividad como muchas manufacturas, pero todos los sectores requieren la aplicación del conocimiento, capital humano calificado, instituciones sólidas y la decisión de aprovechar el acervo mundial de know-how y progreso tecnológico. 
6. En este contexto, el Estado debe erigirse en principal agente impulsor de políticas de elevado impacto multiplicador sobre producto, renta, demanda agregada, empleo productivo de calidad, fomento de oportunidades de ne- gocios y mercados, redistribución, equidad y bienestar social; en este orden lógico, propio del círculo virtuoso del crecimiento sobre la base de la calidad del stock de capital tangible y humano.

\section{Bibliografía}

ALBA TEJEDOR, Carlos y NAVARRO, Carmen. 2004. Análisis y evaluación de políticas públicas. Madrid: UNED.

ALBI, Emilio; GONZALES PÁRAMO, José y ZUBIRI, Ignacio. 2000. Economía pública I. $1^{\mathrm{a}}$ ed. Barcelona: Ariel Economía.

ARCA VERA, José. La carga económica de la enfermedad diarreica aguda en niños menores de 3 años en localidades de la sierra y selva del Perú. 2004. Tesis presentada para optar el grado de magíster en Economía de la Salud en la Universidad Nacional Mayor de San Marcos.

ARROW, Kenneth. 1962: The economic implications of learning by doing. Review of Economic Studies. Jun., vol. 29, n. ${ }^{\circ} 3$, págs.155-173.

BENAVIDES, Óscar. 1998. Tecnología, innovación y empresa. Madrid: Pirámide.

BERCOVICH, Néstor y KATZ, Jorge. 2004. El desarrollo de los complejos forestales en América Latina. Cepal y Alfaomega.

BERGASA PERDOMO, Óscar. 2003. Economía pública moderna. Madrid: Pirámide.

BHIDÉ, Amar V. 2001. Origen y evolución de nuevas empresas. Oxford University Press ( $1^{\mathrm{a}}$ ed. en español).
CEPAL. 2004. Desarrollo productivo en economías abiertas. Santiago de Chile: Cepal.

CHANDLER, Alfred. 1990. Scale and scope, the dynamics of industrial capitalism. Cambridge Mass.: Belknap Press.

COHEN, Michael; MARCH, James y OLSEN, Johan. 1972. A garbage can model of organizacional choice. Administrative Science Quarterly. N. ${ }^{\circ} 17$.

DE FERRANTI, David y otros. 2002: De los recursos naturales a la economía del conocimiento: comercio y calidad del empleo. Washington D.C.: Serie Estudios del Banco Mundial sobre América Latina y el Caribe, 23440.

DURAND, Francisco. 2004. El poder incierto: trayectoria económica y política del empresariado peruano. Lima: Congreso del Perú.

FONDO DE POBLACIÓN DE LAS NACIONES UNIDAS. 2005. Estado de la población mundial: la promesa de igualdad: equidad de género, salud reproductiva y objetivos de Desarrollo del Milenio. Nueva York: UNFPA. [http://www.unfpa.org/ swp/2005/pdf/sp_swp05.pdf].

GALARZA, Elsa. 2003. Desaprovechando las riquezas. El Comercio. Lima, 8 de ago. pág. B2. 
GARCÍA, Uriel. 2005. Medicina y pobreza. El Comercio. Lima, 12 de oct., pág. A5.

GONZALES DE OLARTE, Efraín. 2004a. La difícil descentralización fiscal. Lima: Instituto de Estudios Peruanos.

—. 2004b. Regiones integradas. Lima: Congreso de la República.

GONZALES, Felipe. 2005. Los desafíos de América Latina y el Caribe. $8^{\text {a }}$ Conferencia Cátedra de las Américas, Convenio USMP-OEA, 16 de setiembre.

HAYA DE LA TORRE, Agustín. 2005. La difícil construcción de la comunidad política. Lima: Fundación Friedrich Ebert Stiftung. Aportes al Debate n. ${ }^{\circ} 12$.

2003. Dictadura y democracia. la crisis del Estado republicano. Lima: Foro Democrático.

LAHERA, Eugenio. 2003. Introducción a las políticas públicas. México D. F.: Fondo de Cultura Económica.

2004. Política y políticas públicas. Santiago: Cepal.

MAIDIQUE, Modesto y HAYES, Robert. 1984. The art of high technology management. The Sloan Management Review. Winter, vol. 25, n. $^{\circ}$ 2, págs. 17-31.

MAKÓN, Jorge. 2004. Economía del sector público. Barcelona: Pirámide.

MARTICORENA, Martín. 2005. Unos y otros. Informe en Día_1, El Comercio. Lima, marzo.
MARTÍNEZ ÁLVAREZ, J. A. 2000. Economía del sector público. Barcelona: Bosch Libres.

MEDELLÍN TORRES, Pedro. 1997. Inestabilidad, incertidumbre y autonomía restringida: elementos para una teoría de la estructuración de políticas públicas en países de baja autonomía gubernativa. $R e$ vista del CLAD Reforma y Democracia. Caracas, n. ${ }^{\circ} 8$, mayo.

. 2004. La política de las políticas públicas: propuesta teórica y metodológica para el estudio de las políticas públicas en países de frágil institucionalidad. Santiago: Cepal, julio.

OSZLAK, Óscar. 1980. Políticas públicas y regímenes políticos: reflexiones a partir de algunas experiencias latinoamericanas. Estudios CEDES. Buenos Aires, vol. 3, n. $^{\circ} 2$.

OSZLAK, Óscar y O'DONNELL, Guillermo. 1981. Estado y políticas estatales en América Latina: hacia una estrategia de investigación. Buenos Aires: CEDES/ CLACSO. Documento n. ${ }^{\circ} 4$.

1976. Estado y políticas estatales en América Latina. Buenos Aires: CEDES/ CLACSO. Documento n. ${ }^{\circ} 4$.

PENNY BIDEGARAY, Carlos. 2005. Inversiones forestales privadas: la gran oportunidad. Conferencia organizada por Amcham, Lima, 6 de setiembre.

PÉREZ, Carlota. 2001. Cambio tecnológico y oportunidades de desarrollo como blanco móvil. Revista de la Cepal. Santiago: Cepal, n. ${ }^{\circ} 75$, diciembre. 
PORTOCARRERO, Felipe (ed). 2004. Políticas sociales en el Perú: nuevos aportes. Lima: PUCP y Universidad del Pacífico.

ROCA, Santiago y colab. 2002. La inversión en el Perú 2002-2003: entorno, industrias, regiones, financiamiento y estrategias empresariales. Lima: ESAN.

ROSENBERG, Nathan (comp.). 1979. Economía del cambio tecnológico. México D.F.: Fondo de Cultura Económica.

ROZAS, Patricio y SÁNCHEZ, Ricardo. 2004. Desarrollo de infraestructura y crecimiento económico: revisión conceptual. Santiago: Cepal. Serie 75, Recursos Naturales e Infraestructura, octubre.

SANTACOLOMA, Pilar; SUÁREZ, Ruth y RIVEROS, Hernando. 2005. Fortalecimiento de los vínculos de agronegocios con los pequeños agricultores. Estudios de caso en América Latina y el Caribe. Roma: FAO. AGSF. Documento Ocasional 4.

SCHULDT, Jürgen. 2005. ¿Somos pobres porque somos ricos? Recursos naturales, tecnología y globalización. Lima: Fondo Editorial del Congreso de la República.

SCHUMPETER, Joseph. 1911. La teoría del desenvolvimiento económico. Harvard University Press.
STIGLITZ, J. E. 2000. La economía del sector público. $3^{\mathrm{a}}$ ed. Barcelona: Bosch Libres.

TANZI, Vito. 2000. El rol del Estado y la calidad del sector público. Washington: IMF Working Paper 00/36.

TANZI, Vito y DAVOODI, Hamid. 2000. Corruption, growth and public finance. Washington: IMF. Working Paper 00/182, november.

TOLEDO, Enrique. 2005. Oportunidades de Inversión en negocios forestales. Conferencia de Fondebosques, Lima, 5 de setiembre.

VILLORIA MENDIETA, Manuel. 2002. Control democrático y transparencia en la evaluación de políticas públicas. Ponencia presentada en el VII Congreso Internacional del CLAD sobre la Reforma del Estado y de la Administración Pública. Lisboa, Portugal, 8-11 de oct., 2002.

WEBER, Max. 2003. La ética protestante y el espíritu del capitalismo. México D. F. Fondo de Cultura Económica. $1^{a}$ ed. en español (edición original: 1904-1905).

WISE, Carol. 2003. Reinventando el Estado: estrategia económica y cambio institucional en el Perú. Lima: Centro de Investigación de la Universidad del Pacífico. 